
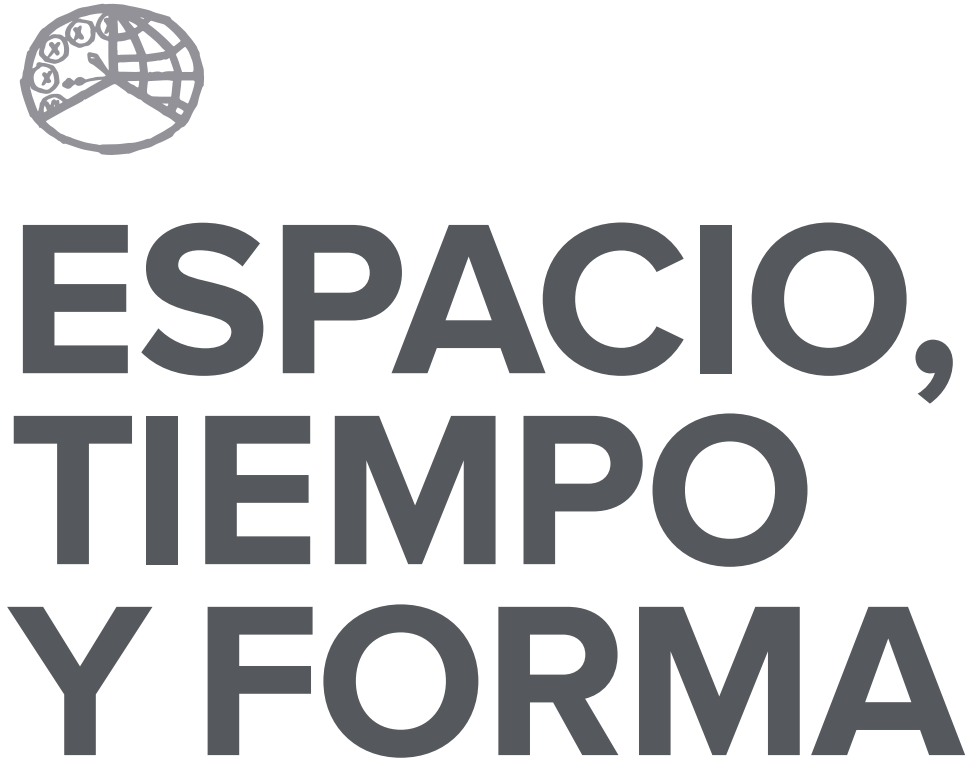

AÑO 2018

ISSN 0214-9745

E-ISSN 2340-1362

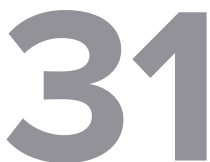

SERIE III HISTORIA MEDIEVAL

REVISTA DE LA FACULTAD DE GEOGRAFÍA E HISTORIA 



\section{ARTÍCULOS · ARTICLES}





\title{
LA MUERTE DEL PRÍNCIPE DON JUAN. EXEQUIAS Y DUELO EN CÓRDOBA Y SEVILLA DURANTE EL OTOÑO DE 1497
}

\section{THE DEATH OF PRINCE JUAN. FUNERAL RITES AND MOURNING IN CORDOBA AND SEVILLE DURING THE AUTUMN OF 1497}

\author{
Margarita Cabrera Sánchez ${ }^{1}$ \\ Recepción: 2017/7/4. Comunicación de observaciones de evaluadores: 2017/10/2. \\ Aceptación: 2017/10/4
}

DOI: http://dx.doi.org/10.5944/etfiii.31.2018.21137

\begin{abstract}
Resumen ${ }^{2}$
La finalidad de este trabajo es estudiar las circunstancias de la muerte del príncipe don Juan, los ritos post mortem y las ceremonias fúnebres que tuvieron lugar en Córdoba y Sevilla. Además, nos hemos detenido a analizar cómo pudieron transcurrir los primeros años de su vida y su adolescencia, ya que los testimonios consultados revelan una salud frágil, que, probablemente, pudo precipitar su temprano fallecimiento. Las numerosas fuentes a las que hemos tenido acceso nos han permitido obtener datos inéditos sobre el ceremonial funerario, las manifestaciones de duelo y el volumen de gastos al que tuvieron que hacer frente los concejos de Córdoba y Sevilla para despedir, como la ocasión merecía, al príncipe heredero.
\end{abstract}

\section{Palabras clave}

Ritual funerario regio; príncipe don Juan; exequias; luto; duelo.

\section{Abstract}

The purpose of this paper is to study the circumstances of the death of prince Juan, the post mortem rites and the funeral ceremonies that took place in Cordoba and Seville. In addition, we have analysed how the first years of his life and adolescence

1. Universidad de Córdoba. C.e.: calcasam@uco.es

2. Este trabajo ha sido realizado en el marco de los proyectos de investigación La muerte del príncipe en Francia yen los reinos hispánicos (s. XI-XV). Modelos de comparación (HAR2016-74846-P MIGRAVIT), financiado por la Agencia Estatal de Investigación del Gobierno de España, y Tecnología y Conocimiento en la Península Ibérica (siglos XIII-XVI) (HAR201567619-P), cofinanciado por el Ministerio de Economía y Competitividad y el Fondo Europeo de Desarrollo Regional. 
may have taken place, since the testimonies consulted reveal a fragile health that probably could have determined his early death. The numerous sources to which we have had access allowed us to obtain unpublished information on the funerary ceremonial, the demonstrations of mourning and the level of expenditure that was assumed by the councils of Cordoba and Seville to pay their last respects to the heir prince.

\title{
Keywords
}

Royal Funeral Ritual; Prince Juan; Obsequies; Grieving; Mourning.

\begin{abstract}
«Estando el rey e reyna nuestros señores en la cibdad de Sevilla en el año de Nuestro Redenptor de mil y quatroçientos y setenta y ocho años, postrimero día de junio, a las honze horas, cerca de mediodía, nasçió el yllustríssimo prínçipe don Juan nuestro señor, a quien Dios haga muy bienaventurado en vida de los sereníssimos rey e reyna nuestros señores, otorgándole muy larga vida a su serviçio e a mayor acreçentamiento destos reynos y señoríos»³.
\end{abstract}

Así relató el cronista Diego de Valera el nacimiento del príncipe don Juan, sin olvidar de desearle una longevidad de la que, desgraciadamente, tal y como podía suceder dada la corta esperanza de vida de la época, no pudo disfrutar el príncipe, ya que, aunque con algunas dificultades consiguió superar esa difícil etapa que era entonces la infancia, murió en plena juventud, recién cumplidos sus ig años.

Hace algún tiempo, en un magnífico e imprescindible libro sobre la figura de don Juan, al referirse a la muerte de este último, A. Alcalá señalaba acertadamente que el príncipe «casi tan sólo es célebre por ella», dado que su existencia «apenas fue sino mero futurible» ${ }^{4} \mathrm{y}$, de hecho, han sido muchos los trabajos que han centrado su atención en el fallecimiento del príncipe, a pesar de que, en cierto modo, todavía hoy, todo lo que rodea su inesperada y prematura muerte siga envuelto en la leyenda. Por ello hemos realizado el presente trabajo, cuyo objetivo es analizar las circunstancias de su fallecimiento, los ritos post mortem y el ceremonial funerario desplegado en algunos lugares de la Península para darle su último adiós. Para conseguir ese fin, hemos utilizado, sobre todo, las noticias que se pueden encontrar en los testimonios cronísticos, las cartas de Pedro Mártir de Anglería y la información proporcionada por Gonzalo Fernández de Oviedo, así como la documentación emanada de algunos concejos municipales, en concreto, los de Córdoba y Sevilla, cuya consulta nos ha facilitado datos absolutamente

3. Valera, Diego de: Crónica de los Reyes Católicos, ed. J. M. Carriazo, Madrid, José Molina impresor, 1927, p. 102.

4. AlCalá Galve, Ángel \& SANz Hermida, Jacobo: Vida y muerte del príncipe don Juan. Historia y literatura. Valladolid, Junta de Castilla y León, 1999, p. 19. Sobre el príncipe don Juan, ver también CARDAILLAC, Louis: L'Espagne des Rois Catholiques. Le prince don Juan, symbole de l'apogée d'un règne, 1474-1497. Paris, Éditions Autrement, 2000. 
desconocidos sobre las ceremonias fúnebres, las manifestaciones de duelo y el volumen de gastos al que tuvieron que hacer frente los concejos de esas dos ciudades para despedir, como la ocasión merecía, al heredero de los Reyes Católicos. Pero, además de abordar el momento de su muerte, nos ha parecido interesante tratar de conocer cómo pudieron transcurrir los primeros años de su vida y su adolescencia, ya que los testimonios que han llegado a nosotros revelan una salud quebradiza que, probablemente, pudo precipitar su temprano fallecimiento.

\section{LA INFANCIA Y ADOLESCENCIA DEL PRÍNCIPE}

Como es fácil suponer, el nacimiento del príncipe don Juan supuso una alegría inmensa, dado que, según refiere Hernando del Pulgar, la reina Isabel llevaba muchos años sin quedarse embarazada ${ }^{5}$, a lo cual hay que añadir que, por fin, esa larga espera fue recompensada con el alumbramiento de un varón. En alguna ocasión, se ha llegado a comparar el «inmenso regocijo» del nacimiento con el «llanto incontenible» que provocó su muerte ${ }^{6}$, algo que, sin duda, es cierto, según habrá ocasión de comprobar.

Seguramente no hay mejor forma de trasladarse al feliz día de su bautizo que consultar la crónica de Andrés Bernáldez. Con gran lujo de detalles, en un texto que rezuma felicidad, el cronista describe lo acontecido en Sevilla aquel 9 de julio de 1478 , recreándose especialmente en la comitiva procesional que condujo al príncipe don Juan hacia la iglesia7. Muchos siglos después, Francisco Pradilla, capaz como pocos pintores de recrear momentos históricos de nuestro pasado medieval, consiguió plasmar de forma magistral, en uno de sus cuadros, la procesión descrita por el cronista Bernáldez y el ambiente festivo que rodeó el bautismo del príncipe, por lo que contemplar ese lienzo permite imaginar cómo pudo transcurrir aquel día de verano de $1478^{8}$.

Como cabía esperar, no poseemos demasiados datos sobre los primeros años de vida del príncipe don Juan y, por tanto, desconocemos si, ya desde la cuna, su salud empezó a mostrar esa fragilidad que se haría patente años después. Sí sabemos que su ama de leche fue Juana de Torres, hermana de Pedro de Torres, secretario de don Juan 9 . Parece más que evidente que esta mujer supo desempeñar la importante tarea que se le había encomendado, ya que, como veremos más

5. Pulgar, Hernando del: Crónica de los señores Reyes Católicos don Fernando y doña Isabel de Castilla y de Aragón, t. 70, Madrid, BAE, 1953, p. 328.

6. Alcalá Galve, Ángel \& Sanz Hermida, Jacobo: op. cit., p. 16.

7. Bernáldez, Andrés: Historia de los Reyes Católicos don Fernando y doña lsabel, t. 70, Madrid, BAE, 1953, pp. $591-592$.

8. El cuadro, titulado Cortejo del bautizo del príncipe don Juan, se encuentra en el Museo del Prado.

9. Fernández de Oviedo, Gonzalo: Batallas y Quinquagenas, t. II, ed. J. Pérez de Tudela y Bueso, Madrid, Real Academia de la Historia, 2000, p. 187 y p. 191. 
adelante, siguió formando parte de la familia real cuando hacía mucho tiempo que el príncipe había dejado de ser un lactante ${ }^{\mathrm{IO}}$.

Las fuentes conservadas permiten constatar los problemas de salud que don Juan empezó a tener a partir de finales de la década de los ochenta. Así, en el Cronicón de Valladolid se indica que, en mayo de I488, el príncipe padeció «disentería con tenasmo e fiebre continua», especificándose, además, que «en el onzeno naciéronle viruelas ${ }^{\text {II }}$. La presencia de esa sintomatología revela obviamente alguna afección de tipo intestinal, por lo que si tenemos en cuenta las consecuencias nefastas que podían tener en aquella época este tipo de dolencias, especialmente entre la población infantili ${ }^{12}$, y a ello le añadimos la presencia de viruelas, es posible que su salud corriese peligro. Además, en un registro del tesorero Gonzalo de Baeza correspondiente al año I490 se señala que la reina ordenó colocar «vna figura del prínçipe, de çera dorada y pintada» y valorada en 5.000 maravedíes en la capilla de la Virgen de la Antigua de la catedral de Sevilla ${ }^{\text {I3 }}$, por lo que pensamos que, tal vez, ese exvoto pudo ofrecerse para agradecer que don Juan hubiese superado esa enfermedad que le aquejó en 1488 .

Por otra parte, los testimonios que poseemos referidos a comienzos de la década de los noventa nos llevan a pensar que, posiblemente debido a su salud endeble, el príncipe seguía un preciso régimen alimenticio, en el cual se incluía la carne de tortuga. De hecho, tenemos constancia documental de que, a mediados de junio de I490, el rey Fernando ordenó que se le enviasen 50 tortugas, ya que «con las otras que le truxeron» don Juan se encontraba mejor ${ }^{14}$. Además, se vuelven a solicitar ejemplares de esos animales casi un mes después ${ }^{15}$-seguramente porque la petición anterior no se había hecho efectiva- y a finales de I49I. En concreto, en una carta otorgada en diciembre de ese año, se hace palpable la desesperación del rey por recibir las tortugas, hasta el punto de ordenar, «sin dilaçión de una sola hora», la búsqueda de esos animales por el reino de Valencia. En ese testimonio se especificaba, además, que cada mes debían enviarse 40 tortugas, por lo que,

10. Se da la circunstancia, además, de que los restos de ambos tuvieron la misma morada: el convento de Santo Tomás de Ávila. En él se encuentra el sepulcro de Juana y de su esposo (AlCALÁ GALVE, Ángel \& SANZ HermidA, Jacobo: op. cit., p. 65) y, como es bien sabido, el del príncipe don Juan.

11. Cronicón de Valladolid, ed. P. Sáinz de Baranda, Madrid, Imprenta de la viuda de Calero, 1848, p. 174.

12. De ello tuve ocasión de ocuparme hace unos años (CABRERA SÁNCHEZ, Margarita: «La muerte de los niños de sangre real durante el Medievo. Aproximación al tema a través de las crónicas», En la España Medieval, 31 (2008), pp. 243-245).

13. Cuentas de Gonzalo de Baeza tesorero de Isabel la Católica, t. I, ed. A. de la Torre y E. A. de la Torre, Madrid, Consejo superior de investigaciones científicas, 1955, p. 370. Sobre los exvotos a la Virgen de la Antigua, ver PEREDA ESPESO, Felipe: Las imágenes de la discordia. Política y poética de la imagen sagrada en la España del Cuatrocientos. Madrid, Marcial Pons, 2007, pp. 181-190. De igual modo, sobre la Virgen de la Antigua, se puede consultar el trabajo reciente de Laguna Paúl, Teresa: «Devociones reales e imagen pública en Sevilla», Anales de Historia del Arte, 23/II (2013), pp. 127-157.

14. Archivo del Reino de Valencia, Epistolarium, libro 596, fol. 72. 1490/06/16. Córdoba. Carta citada por PÉrez Bustamante, Rogelio \& Calderón Ortega, José Manuel: Don Juan príncipe de las Españas (1478-1479). Colección diplomática. Madrid, Dykinson, 1999, pp. 59-60.

15. AGV, Epistolarium, libro 596, fol. 72. 1490/07/14. Córdoba. Carta citada en Idem, p. 61. Imaginamos que esas siglas corresponden al Archivo del Reino de Valencia, aunque en las abreviaturas aparezca una $G$ en vez de una R. 
si no podían encontrarse en el citado reino, las tendrían que hacer llegar desde Mallorca $^{16}$. Y a todo ello hay que añadir las noticias que aporta Gonzalo Fernández de Oviedo sobre el control alimenticio del príncipe. Así, al relatar cómo transcurría la vida cotidiana de este último, señalaba que sus médicos «platicavan con el prínçipe de cómo avía dormido e de las digestiones e cosas convinientes a la conservaçión de su salud ${ }^{17} \mathrm{y}$, de igual modo, al mencionar los alimentos que se guardaban en la habitación del príncipe -se trataba sobre todo de dulces-, no se olvidaba de anotar que fuesen «a propósito de su recreaçión e convinientes a su salud» $\mathrm{y}$ «con acuerdo de sus médicos» ${ }^{18}$. Además, según Pedro Mártir de Anglería, don Juan se había «criado a base de pollos de gallina y de otros alimentos flojos de esta clase, como un inválido» ${ }^{19}$.

Pero, junto a esa vigilancia especial de su alimentación y de su salud, resulta llamativo el hecho de que Gonzalo Fernández de Oviedo señalaba que el ama del príncipe «siempre possava en palaçio» ${ }^{20}$, por lo que, si tenemos en cuenta que el citado cronista empezó a servir al príncipe en $\mathrm{I} 49 \mathrm{I}^{2 \mathrm{I}}$, es evidente que esa mujer seguía al lado de don Juan cuando éste era ya un adolescente y, por tanto, cuando hacía ya mucho tiempo que había finalizado su labor como nodriza. En cualquier caso, aunque es lógico que la vida de un príncipe transcurriera en medio de esas medidas de protección, cabe pensar que, sin duda, el extremo cuidado al que fue sometido tuvo mucho que ver con su frágil estado de salud y, en definitiva, con el desvelo de los reyes por asegurar su supervivencia. Se puede incluso establecer un paralelismo con lo que sucedió, décadas más tarde, con el príncipe Eduardo de Inglaterra. En este caso, las precauciones extremas que puso en práctica su padre, el monarca Enrique VIII, en todo lo concerniente a su cuidado ${ }^{22}$, evidencian de forma muy clara el miedo del rey a perder a su deseado heredero varón. Pero, pese a esa sobreprotección, a los dos príncipes les aguardaba el mismo y fatal destino, dado que ambos murieron muy jóvenes. Como es sabido, aunque Eduardo llegó a ser rey, falleció en I553, víctima de la tuberculosis, unos meses antes de cumplir los 16 años ${ }^{23}$.

16. ARV, Epistolarium, 1491, fol. 116v. 1491/12/28. Sevilla. Carta citada en Idem, p. 66. Imaginamos que esas siglas corresponden al Archivo del Reino de Valencia.

17. Fernández de Oviedo, Gonzalo: Libro de la cámara real del príncipe don Juan, oficios de su casa y servicio ordinario, ed. S. Fabregat Barrios, Valencia, Publicacions de la Universitat de València, 2006, p. 95.

18. Aunque en el texto de alude al «retrete» (Idem, p. 109), es evidente que el término hace referencia a la acepción de «habitación» que aparece recogida en el Diccionario de la Real Academia española. Sobre las comidas cotidianas del príncipe, ver el reciente libro de GONZÁLEZ ARCE, José Damián: La casa y corte del príncipe don Juan (1478-1497). Economía y etiqueta en el palacio del hijo de los Reyes Católicos. Sevilla, Sociedad Española de Estudios Medievales, 2016, pp. 414-416.

19. Se refiere a ello en una carta fechada el 13 de junio de 1497 (Anglería, Pedro Mártir de: Epistolario, Documentos inéditos para la Historia de España, t. IX, ed. J. López de Toro, Madrid, Imprenta Góngora, 1953, pp. 334-335).

20. Fernández de Oviedo, Gonzalo: Libro de la cámara real del príncipe don Juan, oficios de su casa y servicio ordinario, ed. cit., p. 140.

21. Idem, p. 14.

22. Esas precauciones están recogidas en JORDAN, Wilbur Kitchener: Edward VI: the young king. The protectorship of the duke of Somerset. Cambridge/Massachusetts, The Belknap Press of Harvard University Press, 1968, pp. 38-39.

23. Fraser, Antonia: Las seis esposas de Enrique VIII. Barcelona, Vergara, 2005, p. 479. 


\section{AMOR Y MUERTE}

Pese a esos problemas de salud que le aquejaron y a su débil naturaleza, el príncipe don Juan consiguió superar con creces la infancia -algo que sin duda era todo un reto, dada la elevada mortalidad infantil de la época- ${ }^{24}$ y celebrar su matrimonio con Margarita de Austria, por lo que es fácil calibrar la alegría y en cierto modo también la tranquilidad que debieron de experimentar los reyes en ese momento, aunque esa felicidad iba a ser muy efímera. Según señaló Jerónimo Zurita, las velaciones tuvieron lugar en Burgos a comienzos de abril de I497 «con las mayores fiestas que en casamiento de príncipe se hizieron grandes tiempos antes en Castilla» ${ }^{25}$, añadiendo que estas últimas se prolongaron durante muchas jornadas ${ }^{26}$, y Alonso de Santa Cruz también anota que «se hicieron en la corte grandes fiestas ${ }^{27}$.

Pero el príncipe iba a disfrutar poco tiempo de su nuevo estado, ya que, como veremos con detalle más adelante, falleció medio año después de contraer matrimonio. Posiblemente fue esa proximidad entre su muerte y el inicio de su vida conyugal la que llevó a Pedro Mártir de Anglería a relacionar el mal aspecto que presentaba don Juan en el mes de junio del año citado con el exceso de relaciones íntimas de la pareja y, en defintiva, a temer las terribles consecuencias que se podían derivar de ello $^{28}$. Fue así como se fraguó «la leyenda amorosa» del príncipe don Juan, tal y como se ha escrito en alguna ocasión ${ }^{29}$, y el mito del «príncipe que murió de amor», que dio nombre al famoso libro del duque de Maura ${ }^{30}$, si bien, no conviene olvidar que su fallecimiento, como analizaremos enseguida, tuvo que ver, al parecer, con la presencia de una enfermedad, cuyas consecuencias tal vez pudieron ser más graves porque coincidieron con un acusado estado de debilidad, que, por otra parte, en mayor o menor medida, siempre estuvo presente en la vida del príncipe.

Existe la posibilidad de que, poco tiempo antes de morir, don Juan padeciese la viruela, ya que en el Libro de las joyas se hace alusión a una prenda confeccionada

24. Cabrera Sánchez, Margarita: «La muerte de los niños de sangre real durante el Medievo...», pp. 222-248. Se da la circunstancia, además, de que todos los hijos de los Reyes Católicos superaron la infancia (Idem, pp. 224-225), algo que, desde luego, no era lo habitual, tal y como se puede comprobar en Idem, pp. 222-224.

25. ZuRITA, Jerónimo: Historia del rey don Hernando el Cathólico, de las empresas y ligas de Italia, vol. I, introducción G. Redondo y C. Morte, ed. facsímil, Zaragoza, Institución Fernando el Católico, 1999, fol. 118r.

26. Idem, fol. $118 \mathrm{v}$.

27. Santa Cruz, Alonso de: Crónica de los Reyes Católicos, t. I, ed. J. M. Carriazo, Sevilla, Escuela de Estudios Hispano-Americanos, 1951, p. 165.

28. Se refiere a ello en una carta fechada el 13 de junio (Anglenía, Pedro Mártir de: Epistolario, t. IX, ed. cit., p. 334). El cronista Bernáldez, por su parte, antes de mencionar la muerte del príncipe, anota que «ovieron placer el príncipe y la princesa gozando matrimonio como buenos casados», pero no establece ninguna conexión explícita entre esas dos circunstancias (Bernáldez, Andrés: Historia de los Reyes Católicos don Fernando y doña Isabel, t. 70, ed. cit., p. 691).

29. Pérez Bustamante, Rogelio \& Calderón Ortega, José Manuel: op. cit., p. 12.

30. Maura, Duque de: El príncipe que murió de amor. Don Juan, primogénito de los Reyes Católicos. Madrid, Aldebarán Ediciones, 2000. 
en Medina del Campo «estando su alteza de las biruelas» ${ }^{\text {I }}$. No sabemos si realmente enfermó de viruela o si lo que pudo padecer fue otra enfermedad exantemática, e incluso desconocemos en qué momento estuvo enfermo. Sin embargo, sí nos consta que, en mayo de I497, los reyes se dirigieron a Valladolid y después a Medina del Campo y que, al parecer, permanecieron en esta última localidad hasta mediados del mes de septiembre ${ }^{32}$, aunque de la lectura del citado Libro de las joyas se deduce que el príncipe y su esposa estaban todavía en Medina del Campo el día $20^{33}$. Jerónimo Zurita señala que hacia la mitad de ese mes, encontrándose los monarcas en Valencia de Alcántara, les llegó la noticia de que su hijo «auía adolecido» ${ }^{34}$, por lo que, de ser cierta esta información, probablemente fue entonces cuando pudo contraer esa dolencia.

A. Alcalá ya señaló, en su día, que la viruela fue «la raíz del fatal mal»35, aunque realmente es muy difícil saber si el príncipe fue víctima de esa enfermedad. Por un lado, como veremos más adelante, algunos de los síntomas de la viruela como la fiebre y los vómitos ${ }^{36}$ los presentaba don Juan días antes de su muerte, por lo que no podemos descartar que esa grave enfermedad pudiese haber sido la causa del fallecimiento. Sin embargo, hay que tener en cuenta que esa sintomatología puede estar presente en otras muchas dolencias y que, además, en el caso de la viruela, al parecer, la fiebre suele aparecer en la primera fase de la enfermedad, con anterioridad a la erupción cutánea ${ }^{37}$. Desconocemos cuándo pudo presentar el príncipe las características erupciones en la piel típicas de la viruela en el caso de que realmente hubiese tenido esta afección, pero, dado que, según el Libro de las joyas, padeció esa dolencia en Medina del Campo ${ }^{38}$, es bastante probable que, considerando lo complicado que resultaba en aquella época emitir un diagnóstico, las lesiones cutáneas fuesen ya visibles durante su estancia en esa localidad, por lo que sorprende que el cuadro febril hiciera su aparición días después, como se verá a continuación. Por otra parte, no podemos olvidar que, si como ya se indicó, pudo enfermar de viruela muchos años antes, parece poco probable que volviese a contraerla, a no ser que la enfermedad que padeció siendo niño no hubiese sido viruela.

31. Hemos consultado el Libro de las joyas que incluyó, como apéndice de su libro, el duque de Maura (Idem, p. 252). En el denominado Libro de las joyas aparecen detalladas las joyas y prendas de vestir de la princesa Margarita (ALCALÁ GaLVE, Ángel \& SANZ Hermida, Jacobo: op. cit., p. 165).

32. El día 14 de ese mes se encontraban ya en Madrigal (GALíndez de CARVAjAL, Lorenzo: Anales breves del reinado de los Reyes Católicos D. Fernando y doña Isabel, t. 70, Madrid, BAE, 1953, p. 548 y nota 14).

33. Es lo que podemos deducir del hecho de que, entre las prendas de la princesa, se cita un tabardo que se confeccionó ese día en Medina del Campo (MaURA, Duque de: op. cit., pp. 251-252).

34. ZURITA, Jerónimo: Historia del rey don Hernando el Cathólico, de las empresas y ligas de Italia, vol. I, ed. cit., fol. 128 r.

35. Alcalá Galve, Ángel \& Sanz Hermida, Jacobo: op. cit., p. 175.

36. Romero CABello, Raúl: Microbiología y parasitología humana. Bases etiológicas de las enfermedades infecciosas y parasitarias. México, Editorial Médica Panamericana, 2007, p. 348.

37. Ibidem.

38. Maura, Duque de: op. cit., p. 252. 
En cualquier caso, los testimonios conservados se hacen eco de la fiebre que presentaba el príncipe a comienzos de octubre. Según anota Pedro Mártir de Anglería en una de sus cartas, don Juan hizo su entrada en Salamanca el 28 de septiembre, añadiendo que tuvo «una repentina fiebre» a los tres días ${ }^{39} \mathrm{y}$, por tanto, el I de octubre. Por su parte, Alonso de Santa Cruz señala que el príncipe, «al cabo de tres días» de la llegada a esa ciudad, padeció «una grande calentura». Aunque el citado cronista fecha esa entrada el 29 de octubre ${ }^{40}$, es evidente que incurrió en un error a la hora de anotar el mes, por lo que podemos suponer que, si esa llegada tuvo lugar el 29 de septiembre, la fiebre hizo su aparición el 2 de octubre. Por su parte, Jerónimo Zurita especifica que don Juan, «dentro de tres días» de la llegada a Salamanca, que según se deduce de su relato se produjo a finales de septiembre, tuvo «vna fiebre continua» ${ }^{41}$. Desgraciadamente, tal y como era habitual entonces, esos tres autores se limitan a mencionar ese síntoma, que solía acompañar a muy distintas dolencias, pero sin hacer ninguna alusión a la enfermedad que pudo provocar esa fiebre ${ }^{42}$.

Por otra parte, contamos con otro testimonio que permite completar el proceso sintomático que tuvo el príncipe poco antes de su fallecimiento. Así, se conserva una interesante carta del obispo Diego de Deza, que estuvo al cuidado de don Juan en Salamanca ${ }^{43}$. Se trata de una carta dirigida a los reyes y fechada el 29 de septiembre, cuya lectura evidencia que el príncipe apenas comía y que había vomitado, así como la gravedad de su estado, aunque en el texto sólo se alude a «enfermedad» sin aportar ningún dato más al respecto. Lo que sí queda fuera de toda duda al leer esa carta del obispo es su visible preocupación por el estado de salud del príncipe ${ }^{44}$; de hecho, a don Juan le quedaban pocos días de vida.

Por último, no queremos dejar de señalar que la sospecha del envenenamiento, que con frecuencia solía asociarse a los fallecimientos regios ${ }^{45}$, también rodeó la muerte del príncipe, tal y como parece sugerir la lectura de un conocido romance ${ }^{46}$.

39. Se trata de una carta fechada el 19 de octubre (Anglería, Pedro Mártir de: Epistolario, t. IX, ed. cit., pp. 344345). Hemos podido comprobar, además, que esa misma fecha de entrada es la que se recoge en la versión latina de esta obra (Anglería, Pedro Mártir de: Opus epistolarum. Amsterdam, 1670, p. 103).

40. Santa Cruz, Alonso de: Crónica de los Reyes Católicos, t. I, ed. cit., p. 167.

41. ZURITA, Jerónimo: Historia del rey don Hernando el Cathólico, de las empresas y ligas de Italia, vol. I, ed. cit., fol. 128 r.

42. En general, según pudimos ver en su momento, se aportaban muchos más detalles sobre la sintomatología que presentaban muchas dolencias que sobre las propias enfermedades (CABRERA SÁNCHEZ, Margarita: «La muerte de los miembros de la realeza hispánica medieval a través de los testimonios historiográficos», En la España Medieval, 34 (2011), pp. 112-119).

43. Alcalá Galve, Ángel \& Sanz Hermida, Jacobo: op. cit., p. 179.

44. Carta citada en Idem, p. 180.

45. Ver ejemplos en CABRera SÁnCHeZ, Margarita: «La muerte de los miembros de la realeza hispánica...», pp. 125-129.

46. En ese romance, recogido por A. Castro, puede leerse que el doctor de la Parra llevaba «solimán en el dedo, en la boca se lo echara» (CASTRO QueSAdA, Américo: Teresa la Santa, Gracián y los separatismos con otros ensayos. Madrid, Alfaguara, 1972, p. 169). Al posible envenenamiento del príncipe ya se refirieron, en su día, A. Alcalá (ALCALÁ Galve, Ángel \& Sanz Hermida, Jacobo: op. cit., pp. 181-182) y J. L. Gonzalo (Gonzalo Sánchez-Molero, José Luis: «El príncipe Juan de Tastámara, un exemplum vitae para Felipe II en su infancia y juventud», Hispania, LIX/3, 203 (septiembre-diciembre de 1999), p. 896). 
En definitiva, en nuestra opinión, ese cuadro clínico que presentaba don Juan en su lecho de muerte y en el que estuvieron presentes la fiebre, la falta de apetito y los vómitos, parecen apuntar hacia el hecho de que el hijo de los Reyes Católicos no murió «de amor» como pretendía la leyenda, sino como consecuencia de una enfermedad cuya verdadera naturaleza no podemos precisar. Pese a la gran trascendencia política que tuvo la muerte del príncipe don Juan, los historiadores de la época no se ponen de acuerdo a la hora de anotar cuándo se produjo esta última. La mayor parte de ellos la sitúan el día 4 de octubre -así lo hacen Jerónimo Zurita ${ }^{47}$, Lorenzo Galíndez de Carvajal ${ }^{48}$ y Gonzalo Fernández de Oviedo-49, si bien, Andrés Bernáldez la adelanta al día anterior ${ }^{50}$ y Pedro Mártir de Anglería la retrasa al día $6^{51}$.

No poseemos demasiados datos sobre los ritos post mortem que se pusieron en práctica porque las fuentes ofrecen pocos datos en ese sentido. Pese a todo, es muy probable que el cuerpo del príncipe no fuese sometido a ningún tipo de conservación artificial, dado que, al silencio que guardan esas fuentes sobre esta cuestión, hay que añadir el hecho de que, como hemos podido comprobar recientemente, la costumbre de embalsamar cuerpos regios no estaba generalizada en la Península Ibérica a finales de la Edad Media, lo que nos llevó a la conclusión de que no era parte consustancial del ritual funerario de los miembros de la realeza ${ }^{52}$. En todo caso, sí nos consta que, al parecer, el obispo Diego de Deza amortajó a don Juan con el hábito dominico ${ }^{53}$. Por otra parte, la información recogida en algún testimonio que se ha conservado permite deducir que ciertos ritos ligados a la muerte regia no se llevaron a cabo con la solemnidad que la ocasión requería. Así, el relato de Gonzalo Fernández de Oviedo, en el que puede leerse que el príncipe murió «entre las doze e la vna ora después de medianoche» y que sus servidores lo sepultaron «antes quesclaresciese» en la catedral de Salamanca ${ }^{54}$, nos lleva a suponer que entre el momento del óbito y el de la inhumación transcurrieron sólo unas cuantas horas, que, al coincidir además con la madrugada, no eran, desde

47. Zurita, Jerónimo: Historia del rey don Hernando el Cathólico, de las empresas y ligas de Italia, vol. I, ed. cit., fol. 128r.

48. Galíndez de Carvajal, Lorenzo: Anales breves del reinado de los Reyes Católicos Don Fernando y doña Isabel, t. 70 , ed. cit., p. 548 .

49. Fernández de Oviedo, Gonzalo: Libro de la cámara real del príncipe Don Juan, oficios de su casa y servicio ordinario, ed. cit., p. 110.

50. Bernáldez, Andrés: Historia de los Reyes Católicos don Fernando y doña Isabel, t. 70, ed. cit., p. 691.

51. Anglería, Pedro Mártir de: Epistolario, t. IX, ed. cit., p. 346. Por su parte, Alonso de Santa Cruz no especifica la fecha del óbito (SANTA Cruz, Alonso de: Crónica de los Reyes Católicos, t. I, ed. cit., p. 168).

52. Cabrera SÁnCHeZ, Margarita: «Técnicas de conservación post mortem aplicadas a los miembros de la realeza hispánica medieval», Edad Media. Revista de Historia, 16 (2015), p. 177 y «El rey ha muerto: ritos, funerales y entierro de la realeza hispánica medieval», en LóPEz OJEDA, Esther (coord.): De la tierra al cielo. Ubi sunt qui ante nos in hoc mundo fuere?, XXIV Semana de Estudios Medievales. Logroño, Instituto de Estudios Riojanos, 2014, p. 243.

53. Fernández de Oviedo, Gonzalo: Batallas y Quinquagenas, t. III, ed. J. Pérez de Tudela y Bueso, Madrid, Real Academia de la Historia, 2000, p. 340.

54. Avalle-Arce, Juan Bautista: Las memorias de Gonzalo Fernández de Oviedo, vol. I, Chapel Hill, North Carolina Studies in the romance languages and literatures, 1974, p. 296. Como señala el citado autor, se trata de una edición de las Quinquagenas de la nobleza de España (Idem, p. 9). 
luego, las más idóneas para exponer los restos y para organizar un multitudinario cortejo fúnebre hacia el lugar de sepultura, lo cual llama bastante la atención, teniendo en cuenta que se trataba de dar el último adiós al heredero de los Reyes Católicos. Así, sin salirnos del propio círculo familiar de los monarcas, cuando falleció en Burgos el rey Felipe el Hermoso, el 25 de septiembre de 1506 «casi al medio día» según Alonso de Santa Cruz ${ }^{55}$, su cadáver estuvo expuesto hasta el amanecer del día siguiente, momento en que fue embalsamado. Además, gracias al citado cronista sabemos que el cuerpo fue trasladado al monasterio de Miraflores «muy honrradamente» ${ }^{56}$. En el caso del príncipe don Juan, desconocemos las razones que pudieron llevar a esa inhumación tan inmediata, ya que la inexistencia de actas capitulares de I497 en el Archivo Municipal de Salamanca nos ha impedido conocer posibles detalles sobre el traslado del cuerpo hacia la catedral y sobre la celebración de las exequias en esa ciudad. De cualquier modo, parece poco probable que, dada la época del año en la que tuvo lugar el fallecimiento, ese entierro tan apresurado obedeciera al deterioro inminente del cadáver y a la imposibilidad de ser expuesto, por lo que pensamos que, tal vez, la razón haya que buscarla en el carácter provisional que tuvo ese enterramiento. En efecto, nos consta que don Juan fue sepultado en Salamanca «en depósito» en palabras de Gonzalo Fernández de Oviedo ${ }^{57}$, siendo trasladado a Ávila el 8 de noviembre $^{58}$, por lo que es posible que el rey Fernando, consciente de que se trataba de una sepultura transitoria, y a la espera de reunirse con la reina ${ }^{59}$ para decidir el lugar de inhumación definitivo de su hijo, prefiriese dejar para ese último viaje la magnificencia que no podía faltar en los cortejos fúnebres regios y que, según Gil González Dávila, estuvo presente en el traslado a Ávila ${ }^{60}$.

Como cabía esperar, la muerte del joven príncipe provocó una gran conmoción que quedó plasmada en numerosos textos de la época, cuya lectura permite evocar el dolor y el llanto que impregnaron aquel otoño de $1497^{61}$. Pedro Mártir de Anglería dejó escrito que el día de la muerte de don Juan «llenó de profundo luto

55. Santa Cruz, Alonso de: Crónica de los Reyes Católicos, t. II, ed. J. M. Carriazo, Sevilla, Escuela de Estudios Hispano-Americanos, 1951, p. 58.

56. Idem, pp. 59-60.

57. FeRnÁNDEZ DE OVIedo, Gonzalo: Libro de la cámara real del príncipe don Juan, oficios de su casa y servicio ordinario, ed. cit., p. 136.

58. Así consta en una anotación a un documento procedente del Archivo Municipal de esa ciudad citado por Alcalá Galve, Ángel \& SANZ Hermida, Jacobo: op. cit., p. 193 y p. 197.

59. Según Alonso de Santa Cruz, cuando el estado de salud del príncipe se agravó, los reyes se encontraban en Valencia de Alcántara para celebrar el matrimonio de su hija Isabel con el rey de Portugal y sólo el rey Fernando viajó a Salamanca y estuvo presente cuando murió su hijo (SANTA CRUz, Alonso de: Crónica de los Reyes Católicos, t. I, ed. cit., pp. 167-168). Esta misma idea expresa Pedro Mártir de Anglería, si bien, señala que los monarcas estaban en Valencia de don Juan (ANGLería, Pedro Mártir de: Epistolario, t. IX, ed. cit., pp. 345-346).

6o. González DÁvILA, Gil: Historia de las antigvedades de la civdad de Salamanca: vidas de svs obispos y cosas sucedidas en su tiempo. Salamanca, 1606, p. 409.

61. Hace ya más de medio siglo, J. Camón señalaba que el recuerdo de don Juan seguía originando «un eco dolorido en la sensibilidad española» (CAmón AznAR, José: Sobre la muerte del príncipe don Juan. Madrid, Real Academia de la Historia, 1963, p. 47). 
a España entera» ${ }^{62}$ y Jerónimo Zurita señala que «fueron las honras y obsequias las más llenas de duelo y tristeza que nunca antes en España se entendiesse auerse hecho por príncipe ni rey ninguno» ${ }^{63}$. De igual modo, ese duelo se puede palpar también en los testimonios literarios de algunos autores contemporáneos, entre los que destacan Alonso Ortiz y Juan del Encina. El primero, al comienzo de su tratado sobre la muerte de don Juan, especificaba que «lloránronle las çibdades, las villas y lugares» ${ }^{64}$ y Juan del Encina no quiso dejar de anotar, en la última estrofa de un espléndido poema dedicado al fallecimiento del príncipe, que «nos dexa en España muy mucho dolor» ${ }^{65}$.

Pero, además, como analizaremos a continuación, la documentación municipal que se ha conservado constituye también un testimonio primordial para conocer la magnitud del duelo con el que fue despedido don Juan en las ciudades y villas de la Península, lo cual revela el tremendo impacto que provocó su muerte. En concreto, hemos utilizado la documentación municipal de Córdoba y de Sevilla, que nos ha proporcionado datos desconocidos, gracias a los cuales se han reconstruido las exequias del príncipe y las escenas de duelo que se pudieron presenciar en esas dos ciudades andaluzas durante el otoño de I497.

\section{CÓRDOBA DESPIDE AL PRÍNCIPE DON JUAN}

La consulta de las actas del cabildo municipal de Córdoba fechadas en octubre de 1497 permite trasladarnos a aquellos días en los que la ciudad quiso despedirse para siempre del príncipe don Juan. Esa documentación no es todo lo explícita que desearíamos sobre determinados aspectos del ritual funerario que se llevó a cabo, pero, a pesar de ello, como veremos a continuación, los datos que se pueden extraer de esos documentos, la información detallada que ofrecen las actas municipales de otros concejos de la Península sobre la magna despedida de don Juan, así como la vinculación que tuvo el príncipe con Córdoba, ciudad en la que pasó largas temporadas de su corta vida durante el transcurso de las campañas granadinas $^{66}$, nos llevan a suponer que los cordobeses se volcaron de forma especial con ese homenaje póstumo al príncipe, a quien, en cierto modo, habían visto crecer. De hecho, todavía se conserva, entre los fondos notariales cordobeses, una

62. Anglería, Pedro Mártir de: Epistolario, t. IX, ed. cit., p. 346.

63. ZURITA, Jerónimo: Historia del rey don Hernando el Cathólico, de las empresas y ligas de Italia, vol. I, ed. cit., fol. $128 \mathrm{v}$.

64. Ortiz, Alonso: Tratado del fallesçimiento del muy ínclito señor don Juan, ed. J. Sanz Hermida, Ávila, Ediciones de la Institución «Gran Duque de Alba», 2000, p. 51.

65. Encina, Juan del: Obra completa, ed. M. A. Pérez Priego, Madrid, Ediciones de la Fundación José Antonio de Castro, 1996, p. 397. Sobre la numerosa literatura consolatoria centrada en la muerte del príncipe, ver la que recoge J. Sanz (Alcalá Galve, Ángel \& Sanz Hermida, Jacobo: op. cit., pp. 219-372).

66. Como es sabido, entre 1481 y 1492, Córdoba fue la base de operaciones de las campañas granadinas (RUMEU DE ARMAS, Antonio: Itinerario de los Reyes Católicos 1474-1516. Madrid, Consejo superior de investigaciones científicas, 1974, ver la página desplegable que se inserta a continuación de la p. 117). 
anotación inédita en la que puede leerse que la tarde del I5 de mayo de I484 «entró en esta çibdad el prínçipe nuestro señor e las dos ynfantas», especificándose que también habían llegado ese mismo día la reina y la princesa ${ }^{67}$. Y ésa fue sólo una de las muchas ocasiones en las que los vecinos de la ciudad pudieron contemplar el paso de la comitiva del príncipe don Juan, cuando seguramente nada hacía presagiar su temprano fallecimiento.

El tema de la muerte del príncipe se trató en una reunión del concejo cordobés celebrada el lunes i6 de octubre de 1497. En ella, además de quedar establecidas las disposiciones referidas al duelo, de las que nos ocuparemos más adelante, se ordenaba que varios integrantes del concejo fuesen a tratar el tema de las exequias con los miembros del cabildo de la catedral ${ }^{68}$. Sin embargo, en las actas del cabildo catedralicio no hemos encontrado ninguna noticia referente a los funerales del príncipe, por lo que, si a ello añadimos la parquedad de datos que ofrecen en ese sentido las actas municipales, es evidente que resulta complicado conocer los pormenores de sus exequias. No obstante, gracias a una anotación que se inserta a continuación de un acta del día 20 de octubre, sabemos que se celebraron el lunes día $23^{69}$, si bien, la lectura de otra acta municipal permite deducir que se llevó a cabo otro oficio religioso en la catedral durante la tarde del domingo anterior, «a bísperas» ${ }^{70}$. En este último documento se ordenaba que las cofradías tenían que ir a la catedral «con sus candelas» ${ }^{71}$, por lo que podemos suponer que, tal y como era habitual en los funerales regios, se organizó una procesión en dirección al templo catedralicio, que contaría también con la presencia de los miembros de la oligarquía urbana de la ciudad, y en la cual las manifestaciones de duelo de sus integrantes, a la luz de las velas, permitieron escenificar el dolor por la muerte de don Juan. Seguramente esa comitiva procesional no sería muy distinta a las procesiones fúnebres que se organizaron en Écija, Ávila y Murcia en honor al príncipe y de las cuales se ha conservado una minuciosa descripción en la documentación municipal ${ }^{72}$.

67. Archivo Histórico Provincial de Córdoba (AHPC), Protocolos Notariales (PN), 14122P, cuad. 9, fol. 125r. El año 1484 es el que figura al comienzo del cuadernillo 9, por lo que, aunque en la anotación citada no se indica el año, sino sólo el día y el mes, es evidente que esa entrada tuvo lugar en 1484.

68. Archivo Municipal de Córdoba (AMC), Actas capitulares (AACC), L-00004. 1497/10/16. Aunque las actas capitulares no presentan foliación, se pueden localizar fácilmente por la fecha.

69. AMC, AACC, L-00004. 1497/10/20.

70. AMC, AACC, L-00004. 1497/10/18. De hecho, las exequias regias celebradas en Córdoba duraban aproximadamente unos dos días, ya que daban comienzo una tarde y continuaban durante la jornada siguiente (CABrera SÁnchez, Margarita: «Funerales regios en la Castilla bajomedieval», Acta historica et archaeologica mediaevalia, 22/2 (2001), p. 541).

71. AMC, AACC, L-00004. 1497/10/18.

72. Archivo Municipal de Écija, Actas capitulares, leg. 1, fols. 421v.-425V. 1497/10/16. Écija. Documento citado por Rufo Ysern, Paulina: «El príncipe don Juan de Trastámara, señor de Écija», Historia. Instituciones. Documentos, 31 (2004), p. 624 y p. 628 . Como se puede comprobar al leer el documento, este último está fechado el día 16 de octubre, a pesar de que en la cabecera del mismo conste el día 6. Sobre Ávila, ver un documento procedente del Archivo Municipal de esa ciudad citado por AlCalÁ Galve, Ángel \& SAnz Hermida, Jacobo: op. cit., p. 193 y p. 197. Sobre Murcia, ver García PÉrez, Francisco José \& González ARCE, José Damián: «Ritual, jerarquías y símbolos en las exequias reales de Murcia (siglo XV)», Miscelánea Medieval Murciana, XIX-XX (1995-1996), pp. 135-136. 
Desconocemos la escenografía que pudo presentar la catedral de Córdoba con motivo de las honras fúnebres de don Juan porque las actas municipales sólo hacen alusión a «dozientas hachas e la otra çera que será menester» ${ }^{73}$, lo que impide conocer realmente el número total de velas que iluminaron el interior del templo. De todas formas, esas 200 ya revelan de forma evidente la magnificencia de las exequias del príncipe, ya que el número de velas fue casi el doble de las utilizadas en las honras de la reina Isabel, ocasión en la que se emplearon I0 $4^{74}$. Por otra parte, tampoco hemos encontrado ningún dato sobre los tejidos de luto que pudieron decorar la catedral cordobesa y que, como es sabido, eran, junto con los cirios, el elemento que ponía esa nota luctuosa e imprescindible en este tipo de escenarios. Por tanto, nos vemos obligados a utilizar, como elemento comparativo, las noticias referidas a las exequias que se celebraron en memoria del príncipe en otros lugares. Así, en el caso de Écija, la documentación nos ayuda a imaginar el interior de la iglesia de Santa Cruz tapizado de luto e iluminado por multitud de velas, hasta el punto de especificarse que «la çera que avía eran CX hachas, que no cabían más» ${ }^{75}$. En cualquier caso, la pieza fundamental de ese lúgubre decorado que lució la catedral de Córdoba fue, sin duda alguna, el túmulo funerario levantado en honor al príncipe y del que, lamentablemente, no poseemos ninguna información. Sin embargo, según pudieron comprobar F. J. García y J. D. González, en Murcia, durante el siglo XV, las camas utilizadas durante el ceremonial funerario regio tenían forma de túmulos cuyas alturas oscilaban entre 8 y Io gradas $^{76} \mathrm{y}$, de igual modo, sabemos que en la citada iglesia de Santa Cruz de Écija se colocó una construcción de I4 gradas y encima se situó una cama, sobre la cual «se puso su pauellón de sargas negras bien alto» ${ }^{77}$, por lo que seguramente el monumento efímero que se emplazó en la catedral cordobesa no fue muy diferente de los anteriores.

Lo que sí parece fuera de toda duda es que las exequias del joven príncipe contaron con una gran asistencia de público, a juzgar por el hecho de que en una reunión del concejo municipal se dispuso que se debían recoger los bancos de las iglesias de Córdoba «para lleuar a la iglesia mayor en que se asienten $»^{78}$, lo que indica que el número de asientos de la catedral era insuficiente para las personas que se iban a dar cita allí. No es difícil trasladarse mentalmente a aquel día e imaginar el templo principal de la ciudad abarrotado de cordobeses rigurosamente enlutados, si tenemos en cuenta las estrictas disposiciones referentes al luto que

73. AMC, AACC, L-00004. 1497/10/16.

74. Así se especifica en un acta municipal (AMC, AACC, L-00012. 1504/12/04).

75. De la lectura de un documento podemos deducir que, además de esas 110 velas, había más alrededor de la cama (Archivo Municipal de Écija, Actas capitulares, leg. 1, fols. 421v.-425v. 1497/10/16. Écija. Documento citado por Rufo YSERN, Paulina: «El príncipe don Juan...», p. 624 y p. 627).

76. García Pérez, Francisco José \& GonzÁlez ArCE, José Damián: «Ritual, jerarquías y símbolos...», pp. 131-132.

77. Archivo Municipal de Écija, Actas capitulares, leg. 1, fols. 421v.-425V. 1497/10/16. Écija. Documento citado por RUfo YSERN, Paulina: «El príncipe don Juan...», p. 624 y p. 627.

78. AMC, AACC, L-00004. 1497/10/20. 
habían adoptado los miembros del cabildo municipal, según las cuales se imponía el uso de la jerga ${ }^{70}$ para «los ofiçiales e casa del cabildo», «los francos de la capilla de los reyes y del alcáçar» y los jurados, alcaldes y alguaciles de las villas de Córdoba. Junto a esas medidas, se estipularon otras de carácter más general y, de ese modo, se prohibió llevar, bajo pena de destierro durante un año, «vestidura de seda nin brocado» y trajes o tocados de color rojo, morado o amarillo, afectando esta última disposición tanto a los peatones como a las personas que cabalgaran por la ciudad. Además, a lo largo de nueve días, las mujeres no podían ir por la calle sin usar tocas de color negro ${ }^{80}$. Se trataba, en cualquier caso, de acuerdos muy similares a los que se adoptaron en otros concejos de la Península, según ha quedado constancia en la documentación conservada ${ }^{81}$.

Sin duda, la tristeza por la muerte de don Juan se dejó sentir aquellos días por cada rincón de Córdoba, dadas las drásticas disposiciones de duelo que tomaron los miembros del concejo. Así, por una parte, se paralizó la actividad laboral, ya que se ordenó el cierre de las tiendas durante el día de las honras y el anterior, imponiéndose una pena de 30 días en prisión, y se impidió que los barberos afeitasen, bajo pena de ser desterrados durante un año ${ }^{82}$. Es evidente que con esta última disposición se pretendía favorecer esa práctica consustancial al duelo que consistía en mesar el cabello y la barba y de la cual constituyen un impresionante testimonio gráfico las escenas de plañideros procedentes de los sepulcros de Sancho Sánchez Carrillo y de su esposa que se custodian en el Museo de Arte de Cataluña. Por otra parte, se adoptaron medidas encaminadas a exteriorizar el dolor por la pérdida del príncipe, dado que quedaron suprimidas las «bodas con fiestas» y juglares, imponiéndose una pena de «treynta açotes» para los juglares, así como las escuelas «de dançar» en las casas, especificándose que se romperían las vihuelas y se aplicarían penas de tipo físico ${ }^{83}$. En otros lugares de la Península no se podían celebrar bodas y tampoco bautizos utilizando instrumentos musicales ${ }^{84}$ y se prohibieron los corros, los bailes y «otros juegos de alegría» ${ }^{85}$, ya que, como puede leerse en un precioso documento procedente del Archivo Municipal de Ávila y en el que ha quedado plasmado magistralmente el duelo por el príncipe, «en el tiempo de dolor, tristura e pesar no es razón de fazer auctos

79. Según el Diccionario de la Real Academia española, la jerga es una «tela gruesa y tosca».

80. AMC, AACC, L-00004. 1497/10/16.

81. En concreto, nos referimos a la documentación relativa a Écija (Archivo Municipal de Écija, Actas capitulares, leg. 1, fols. 421V.-425V. 1497/10/16. Écija. Documento citado por RuFO YSERN, Paulina: «El príncipe don Juan...», p. 624 Y p. 626) y a Ávila (documento procedente del Archivo Municipal de esa ciudad citado por ALCALÁ GALVE, Ángel \& SANZ HermidA, Jacobo: op. cit., p. 193 y p. 196).

82. AMC, AACC, L-00004. 1497/10/16

83. AMC, AACC, L-00004. 1497/10/16.

84. Sucedió así en el caso de Ávila, según consta en un documento procedente del Archivo Municipal de esa ciudad citado por Alcalá Galve, Ángel \& SAnz Hermida, Jacobo: op. cit., p. 193 y p. 196.

85. Así se acordó en Écija (Archivo Municipal de Écija, Actas capitulares, leg. 1, fols. 421v.-425V. 1497/10/16. Écija. Documento citado por RUFO YSERN, Paulina: «El príncipe don Juan...», p. 624 y p. 626). 
de plazer e alegría» ${ }^{86}$. Sin duda, el fallecimiento en plena juventud de don Juan fue uno de esos momentos marcados de manera especial por el dolor, hasta tal punto que, seguramente a lo largo de toda la Historia de España, pocas muertes regias causaron tanta conmoción como la que provocó el fallecimiento del hijo de los Reyes Católicos.

La documentación municipal cordobesa no nos permite conocer el volumen total de gastos que ocasionaron los funerales de don Juan. Sin embargo, como veremos a continuación, los problemas que tuvo el concejo de la ciudad para hacer frente a la inversión realizada y la cuantía aproximada que pudo suponer alguna partida concreta, ponen de manifiesto que la despedida del príncipe supuso un esfuerzo económico considerable para la hacienda municipal. Así, en la primera reunión del cabildo municipal en la que se trató el tema de las exequias, celebrada el i6 de octubre, ya se pidió ayuda económica a un genovés llamado Cristóbal ${ }^{87}$ y sólo dos días después, en otra asamblea concejil, se ponía de manifiesto que los préstamos realizados eran insuficientes, por lo que se pedía de nuevo la colaboración económica de los vecinos ${ }^{88}$.

Probablemente, las partidas destinadas al luto ocuparon una parte importante del total de gastos, si tenemos en cuenta que, según consta en un acta municipal, se entregaron «a los ofiçiales e casa del cabildo a cada veynte varas de xerga a cada vno para lobas e capirotes e guarniçiones de syllas e coraças de syllas» ${ }^{89}$. Como es sabido, tanto la loba, que era una prenda talar y con vuelo ${ }^{90}$, como los capirotes o tocados terminados en una cola que recaía sobre la espalda, se utilizaban en señal de duelo ${ }^{91}$, por lo que es evidente que el uso de esas piezas de indumentaria por parte de los miembros del concejo era fundamental para demostrar el dolor por la muerte del príncipe. No sabemos realmente si en ese reparto de tejido de luto se incluyeron todas las personas que desempeñaban algún oficio en el cabildo municipal de Córdoba, si bien, la lectura del acta citada con anterioridad ${ }^{92}$ y de varios documentos municipales referidos a otros concejos parecen apuntar en esa dirección ${ }^{93}$. Sin embargo, desconocemos la composición exacta del concejo cordobés a finales del Medievo en términos cuantitativos, por lo que sólo podemos establecer cálculos estimativos sobre el coste total de la jerga que se entregó a los integrantes del cabildo. Así, gracias a un interesante e imprescindible trabajo

86. Documento citado por AlcalÁ Galve, Ángel \& SAnz HermidA, Jacobo: op. cit., p. 193 y p. 196.

87. AMC, AACC, L-00004. 1497/10/16.

88. AMC, AACC, L-00004. 1497/10/18.

89. AMC, AACC, L-00004. 1497/10/16.

90. Bernis Madrazo, Carmen: Trajes y modas en la España de los Reyes Católicos, vol. II. Los hombres. Madrid, Instituto Diego Velázquez del Consejo superior de investigaciones científicas, 1979, p. 18.

91. Idem, p. 29. Sobre la loba y el capirote de duelo, ver la figura 68 que aparece recogida en este libro.

92. AMC, AACC, L-00004. 1497/10/16.

93. Nos referimos a la documentación relativa a Écija (Archivo Municipal de Écija, Actas capitulares, leg. 1, fols. 421v.-425V. 1497/10/16. Écija. Documento citado por RUFO YSERN, Paulina: «El príncipe don Juan...», pp. 624-625) y a Ávila (documento procedente del Archivo Municipal de esa ciudad citado por AlCALÁ GALVE, Ángel \& SANZ HERMIDA, Jacobo: op. cit., pp. 193-194). 
sobre el concejo cordobés a finales de la Edad Media realizado por J. L. del Pino, hemos podido contabilizar a II9 personas desempeñando algún cargo municipal en Córdoba, aunque hemos de precisar que se trata de una cifra meramente orientativa $^{94}$. No poseemos datos referidos al coste de la vara de jerga en Córdoba en el año I497, aunque sí nos consta que en Sevilla, con motivo de las exequias del príncipe, la inmensa mayoría de la jerga que se entregó a los miembros del concejo municipal estaba valorada en 20 maravedíes la vara ${ }^{95}$, por lo que, considerando que en Córdoba las varas de jerga utilizadas tuviesen un coste similar y teniendo en cuenta ese número aproximado de iıg miembros del cabildo a cada uno de los cuales se le pudieron entregar 20 varas, podríamos calcular un gasto de 400 maravedíes por cada integrante del concejo cordobés y, por tanto, un desembolso aproximado de 47.60o maravedíes en ropas de luto, aunque se trata -insistamos en ello- de un cálculo meramente estimativo. Por otra parte, como es obvio, a esta partida destinada a equipar convenientemente a los miembros del cabildo habría que sumar el coste de las tapicerías de luto que decorarían la catedral de Córdoba y del catafalco levantado en el templo, a todo lo cual hubo que añadir el gasto en cirios, que, junto con todos aquellos elementos inherentes al ceremonial fúnebre regio -escudos y pendones-, estarían presentes tanto en el edificio catedralicio como en el desfile procesional que organizó la ciudad para despedir a don Juan ${ }^{96}$. En definitiva, todo ello permite calibrar el ingente esfuerzo económico que, sin duda, hizo el concejo cordobés, muy similar tal vez al que tuvo que afrontar el concejo sevillano, según tendremos ocasión de comprobar a continuación.

94. Es la cifra que hemos obtenido tras analizar el recorrido detallado que hace el citado autor por los distintos oficios (PINO GARCíA, José Luis del: «El concejo de Córdoba a fines de la Edad Media: estructura interna y política municipal», Historia. Instituciones. Documentos, 20 (1993), pp. 358-374). Sin embargo, a la hora de realizar esa suma, hemos tenido en cuenta que en el concejo de Córdoba había dos alcaldes mayores (CABRERA SÁnchez, Margarita: Nobleza, oligarquía y poder en Córdoba al final de la Edad Media. Córdoba, Servicio de Publicaciones de la Universidad de Córdoba y Obra Social y Cultural de Cajasur, 1998, p. 78) y se han contabilizado sólo 24 regidores del número, ya que desconocemos realmente cuántas regidurías acrecentadas podía haber en ese momento en la ciudad (Idem, p. 102). De igual modo, hemos tenido en cuenta a los alcaldes de la hermandad, ya que, aunque el citado autor señala que el oficio estuvo menos relacionado con el concejo cordobés (PINO GARCíA, José Luis del: «El concejo de Córdoba a fines...», p. 374), esos alcaldes, según un acta municipal, debían llevar jerga (AMC, AACC, L-00004. 1497/10/16). Por otra parte, hay que tener en cuenta que se desconoce el número de fieles que tuvo el concejo (PINO GARCíA, José Luis del: «El concejo de Córdoba a fines...», p. 374), por lo que no los hemos podido contabilizar. De igual modo, tampoco se han incluido, en el cómputo total, a los lugartenientes de los alcaldes mayores y del alguacil mayor, que posiblemente pudieron recibir también tejidos de luto (ver, sobre ellos, CABRERA SÁNCHEZ, Margarita: Nobleza, oligarquía y poder en Córdoba..., pp. 86-100).

95. Se entregaron 1.850 varas a 20 maravedíes la vara y 247 varas a 5 maravedíes la vara (Archivo Municipal de Sevilla (AMS), sección XV, Papeles del mayordomazgo, caja 83, rollo 695, fot. 77. 1497/12/o1). La documentación que se conserva en esta sección de Papeles del mayordomazgo se encuentra microfilmada, por lo que, dado que los documentos no presentan foliación, hemos indicado el rollo de microfilm y el fotograma en el que da comienzo cada documento.

96. Sobre el uso de escudos y pendones utilizados en la comitiva fúnebre del príncipe que se organizó en Murcia ver la información detallada que ofrecen García Pérez, Francisco José \& GonZÁLez ARCE, José Damián: «Ritual, jerarquías y símbolos...», pp. 135-136. 


\section{LAS EXEQUIAS DEL PRÍNCIPE EN SEVILLA}

La interesante documentación que se conserva en la sección de Papeles del mayordomazgo del Archivo Municipal de Sevilla nos permite conocer numerosos pormenores sobre la despedida póstuma del príncipe don Juan. Aunque esos documentos se refieren a los gastos que hizo el concejo sevillano con motivo de la celebración de las honras fúnebres, la precisión con la que aparecen anotados los materiales que se utilizaron para construir y decorar el monumento funerario de la catedral nos ayuda también a reconstruir la escenografía de las exequias. Además, se da la circunstancia de que, en el caso de Sevilla, entre las actas municipales de I497 no se conserva ninguna referida a las honras fúnebres del príncipe, por lo que la documentación citada constituye la fuente fundamental para saber cómo se desarrollaron estas últimas. Por otra parte, hemos conseguido recabar datos desconocidos hasta ahora, ya que sólo aparecen recogidas unas breves pinceladas al respecto en un trabajo publicado hace ya más de dos décadas ${ }^{97}$.

En los documentos pertenecientes a la sección mencionada con anterioridad no se indica de forma explícita la fecha de celebración de las honras del príncipe. Sin embargo, nos consta que las obras que se realizaron en la catedral de Sevilla con motivo de las exequias finalizaron el martes 3I de octubre ${ }^{98}$ y que la construcción se desmontó el viernes y el sábado siguientes ${ }^{99}$, por lo que es evidente que las honras se llevarían a cabo el miércoles día I de noviembre y el jueves 2 , si tenemos en cuenta, además, que, al parecer, en unas ordenanzas que se promulgaron en Sevilla con motivo de las exequias de Juan II, se especificaba que estas últimas se extendían durante dos jornadas ${ }^{100}$.

No se ha conservado ninguna descripción sobre el monumento efímero que se instaló en el templo sevillano, aunque los datos que se pueden extraer de la documentación nos ayudan a hacernos una idea de sus dimensiones e incluso de su decoración. Así, se pagaron 42I jornales a los carpinteros, mozos y peones que estuvieron trabajando en las obras a lo largo de io días -entre el i9 y el 3i de octubre, exceptuando el domingo 22 , el sábado 28 y el domingo 29- ${ }^{\text {ror }}$, lo que supone una media de 42 trabajadores diarios. Es evidente que el elevado número de obreros y la inversión de horas realizada son una prueba palpable de la envergadura de la construcción, que, por otra parte, tuvo que destacar por sus elementos decorativos,

97. Romero Abad, Antonio del Rocío: «Fiestas de la vida y de la muerte en la Sevilla del siglo XV», Las ciudades andaluzas (siglos XIII-XVI), Actas del VI Coloquio Internacional de Historia Medieval de Andalucía, Estepona, 199o, LóPEZ DE CoCA CASTAÑER, José Enrique \& GaLÁN SÁNCHEZ, Ángel (coords.), Málaga, Universidad de Málaga, 1991, pp. 294-296.

98. En el documento correspondiente se indica que el día 31 fue sábado, aunque se trata de un error, ya que en ese mismo testimonio se especifica que el 19 fue jueves (AMS, sección XV, Papeles del mayordomazgo, caja 83, rollo 695, fot. 80. 1497/11/30).

99. Así se señala en un documento sin fecha en el que se alude a las obras realizadas entre el 19 y el 31 de octubre (AMS, sección XV, Papeles del mayordomazgo, caja 83, rollo 695, fot. 82).

100. Romero ABAD, Antonio del Rocío: «Fiestas de la vida y de la muerte...», p. 295.

101. El documento carece de fecha (AMS, sección XV, Papeles del mayordomazgo, caja 83, rollo 695, fot. 82). 
aunque manteniendo ese tono lúgubre que no podía faltar en este tipo de escenarios. Así, sabemos que se «pintó de prieto en la yglesia mayor toda la obra de madera ${ }^{102}$, es decir, de tonalidad muy $\operatorname{oscura}^{103}$ y que, además, se emplearon 650 «panes de oro fino», 664 «panes de oro baxo» y 250 de plata ${ }^{104}$ y se construyeron unos arcos de madera de álamo ${ }^{\mathrm{IO}}$.

Como es lógico, el elemento primordial de esa construcción fue el túmulo levantado en honor al príncipe. Un carpintero llamado Juan de Écija construyó la cama, en la cual se colocaron «quatro cabeças con sus rostros de yeso», realizadas por un florentino llamado micer Alberto $^{\mathrm{Io}}$. Sin embargo, no poseemos más datos sobre el aspecto que pudo tener el túmulo, aunque seguramente se colocó una construcción de gradas y encima se situó la cama, tal y como se hizo en la iglesia de Santa Cruz de Écija cuando tuvieron lugar las exequias del príncipe ${ }^{\mathrm{Io}}$, según señalamos con anterioridad. Por otra parte, en el caso de Sevilla, en uno de los documentos consultados se alude al escudo, cotas, banderas, pendones y 70 lanzas $^{\mathrm{108}}$ y en otro testimonio documental se mencionan cuatro mazas de palo $^{\text {I09 }}$. Sin duda, al margen del protagonismo de algunos de esos elementos en la procesión fúnebre que precedió a la celebración de las exequias, y a la que aludiremos con posterioridad, es evidente que también serían utilizados por quienes se encargaron de escoltar el túmulo funerario de don Juan, lográndose, de ese modo, una escenografía similar a la que presentó la mencionada iglesia de Santa Cruz de Écija ${ }^{\text {IIo }}$ o incluso la propia catedral de Sevilla en I454, durante las exequias de Juan $\mathrm{II}^{\mathrm{II}}$. De hecho, el escudo y los pendones resultaban imprescindibles en cualquier funeral regio, dado que, como señaló en su día J. M. Nieto, el primero simbolizaba «la cara más efímera de la idea de poder real» ${ }^{\mathrm{II}}$, en tanto

102. AMS, sección XV, Papeles del mayordomazgo, caja 83, rollo 695, fot. 77. 1497/12/o1.

103. El Diccionario de la Real Academia española define el color prieto como «muy oscuro y que casi no se distingue del negro».

104. AMS, sección XV, Papeles del mayordomazgo, caja 83, rollo 695, fot. 77. 1497/12/01.

105. AMS, sección XV, Papeles del mayordomazgo, caja 83, rollo 695, fot. 80. 1497/11/30.

106. AMS, sección XV, Papeles del mayordomazgo, caja 83, rollo 695, fot. 77. 1497/12/01.

107. Archivo Municipal de Écija, Actas capitulares, leg. 1, fols. 421v.-425V. 1497/10/16. Écija. Documento citado por RUFO YSERN, Paulina: «El príncipe don Juan...», p. 624 y p. 627.

108. En ese documento aparece recogida la palabra «tocas» (AMS, sección XV, Papeles del mayordomazgo, caja 83, rollo 695, fot. 77. 1497/12/o1), aunque es obvio que se trata de un error, dado que, en la misma sección de Papeles del mayordomazgo, aparece un documento que es prácticamente una repetición del anterior y en él puede leerse claramente «cotas». Aunque en este documento no consta la fecha, deducimos la misma del documento citado anteriormente (AMS, sección XV, Papeles del mayordomazgo, caja 83, rollo 695, fot. 88. 1497/12/o1). Las 70 lanzas se mencionan en la partida que se inserta antes de la fecha del primero de los documentos citados (AMS, sección XV, Papeles del mayordomazgo, caja 83, rollo 695, fot. 77. 1497/12/o1).

109. AMS, sección XV, Papeles del mayordomazgo, caja 83, rollo 695, fot. 75. 1498/06/22.

110. Archivo Municipal de Écija, Actas capitulares, leg. 1, fols. 421v.-425V. 1497/10/16. Écija. Documento citado por RUFO YSERN, Paulina: «El príncipe don Juan...», p. 624 y p. 627.

111. Romero Abad, Antonio del Rocío: «Fiestas de la vida y de la muerte...», pp. 295-296.

112. Nieto Soria, José Manuel: Ceremonias de la realeza. Propaganda y legitimación en la Castilla Trastámara. Madrid, Nerea, 1993, p. 191. 
que el pendón del rey era el «símbolo institucional por excelencia del poder real y de la institución monárquica» ${ }^{\mathrm{II}}$.

Por lo demás, cabe imaginar la catedral sevillana ataviada de luto, ya que un testimonio documental hace referencia a varas de luto y, aunque no se indica su finalidad, dado que en ese mismo documento se alude a la jerga que se entregó a los miembros del concejo ${ }^{114}$, suponemos que esas varas de luto o, al menos parte de ellas, se utilizarían para decorar el interior del templo, que, por otro lado, estuvo abarrotado de velas, a juzgar por el hecho de que se realizaron 370 antorcheras «de fojas de fierro» para colocar las hachas, a las que habría que añadir las antorcheras que se arreglaron -desconocemos cuántas eran- ${ }^{\mathrm{II} 5}$ y que imaginamos fueron también utilizadas. Además, según otro testimonio documental, el volumen total de hachas amarillas y blancas y de pequeño y gran tamaño ascendió a I.299 ${ }^{\mathrm{II} 6}$. Se trata, sin lugar a dudas, de una cantidad realmente elevada, por lo que, incluso teniendo en cuenta que parte de esas velas se emplearía en la comitiva procesional, es evidente que, a la luz de ese ingente número de hachas, la catedral de Sevilla lució la estética luctuosa indispensable en los funerales regios. Como es sabido, los elementos de iluminación tenían un papel protagonista en los decorados fúnebres de los miembros de la realeza, como se constata en los testimonios que han llegado a nosotros. Así, por ejemplo, en I483, cuando falleció la reina Carlota de Saboya ${ }^{\mathrm{II}}$, cerca de 700 velas alumbraron la capilla ardiente, el coro y los altares de la iglesia de Notre-Dame de Cléry ${ }^{\mathrm{II}}$.

Por otra parte, las exequias tuvieron que ser multitudinarias, ya que, además de que contarían con la presencia de los vecinos de la ciudad, a ellas acudieron también personas procedentes de otros lugares del reino de Sevilla, tal como se puede comprobar en un documento en el que se hace referencia a un correo que se dirigió a las localidades de Alcalá y Villanueva «a llamar los caualleros y regidores que vengan al día de las honrras» y a otra persona que fue a Alcalá de Guadaíra «al conbidar del adelantado». En ese testimonio no se indica la identidad de este último ${ }^{\text {II }}$, aunque pensamos que se trata de Francisco Enríquez de

113. Idem, p. 193.

114. AMS, sección XV, Papeles del mayordomazgo, caja 83, rollo 695, fot. 77. 1497/12/o1.

115. AMS, sección XV, Papeles del mayordomazgo, caja 83, rollo 695, fot. 77. 1497/12/o1.

116. Se trata de un documento sin fecha en el que las hachas aparecen recogidas en cuatro columnas, en cada unas de las cuales se computan, respectivamente, 809, 276, 102 y 112 hachas, si bien, en esta última columna la suma total anotada asciende a 122, aunque, como se puede comprobar, es un error. Además, como también puede observarse, hay dos columnas que están repetidas (AMS, sección XV, Papeles del mayordomazgo, caja 83, rollo 695, fot. 92). Sobre la elaboración de velas, ver CóRDOBA DE LA LLAVE, Ricardo: La industria medieval de Córdoba. Córdoba, Obra Cultural de la Caja Provincial de Ahorros de Córdoba, 1990, pp. 360-364.

117. Gaude-Ferragu, Murielle: «L'honneur de la reine: la mort et les funérailles de Charlotte de Savoie (1 ${ }^{\mathrm{er}}-14$ décembre 1483)», Revue historique, 652 (octubre de 2009), p. 782.

118. Idem, pp. 796-797.

119. Por otra parte, creemos que, seguramente, las dos localidades que hemos citado en primer lugar son Alcalá de Guadaíra y Villanueva del Río y Minas, aunque el nombre de Villanueva no aparece del todo claro en el documento (AMS, sección XV, Papeles del mayordomazgo, caja 83, rollo 695, fot. 77. 1497/12/o1). 
Ribera, que ocupó el cargo de Adelantado de Andalucía entre 1492 y $1509^{\text {I20 }}$. Sin duda, todos estos miembros de la nobleza, junto con los integrantes del concejo sevillano, pudieron presenciar la ceremonia fúnebre sin perder detalle, utilizando posiblemente los «asientos para los caualleros e señores» que realizó el carpintero Juan de Écija ${ }^{\text {I2I }}$, al que hicimos alusión anteriormente. Desconocemos los pormenores de las exequias, aunque la documentación permite suponer que estuvieron precedidas por una comitiva procesional encaminada hacia la catedral. Así, sabemos que se adquirieron 2Io varas de lienzo teñidas «de prieto», es decir de tonalidad muy oscura, "para las vanderas que se avían de sacar» ${ }^{122}$ y 540 varas de jerga para realizar las cubiertas de los 30 caballos «en que auían de yr las vanderas ${ }^{123}$. Sin duda, el ondeado de las banderas de luto y la presencia de todos esos caballos enjergados, así como de los miembros de la aristocracia y de los integrantes del estamento eclesiástico, que convenientemente enlutados ocuparían un lugar destacado en la procesión, era la mejor forma de demostrar el dolor por la muerte del joven príncipe.

En cualquier caso, la documentación que se contiene en la sección de Papeles del mayordomazgo, además de ayudarnos a imaginar cómo pudieron ser las exequias sevillanas de don Juan, constituye una fuente de primer orden para conocer el volumen de gastos derivados de las honras fúnebres. Según han puesto de manifiesto algunos autores, la escasez de estudios referidos al coste de la muerte regia contrasta con los trabajos en los que se estudia la significación política y simbólica de esta última ${ }^{\mathrm{I2}}$, por lo que el análisis de esos documentos inéditos contribuye, sin duda, a llenar ese vacío historiográfico. Además, se da la circunstancia de que en la citada documentación aparecen registradas, hasta el más mínimo detalle, las diferentes partidas de gastos, lo que permite calcular el coste total de las exequias del príncipe, algo que no es fácil encontrar en los trabajos referidos a funerales regios, en los que la documentación utilizada casi siempre suele proporcionar datos referidos sólo a algunas partidas concretas ${ }^{125}$.

Como era previsible, dada la enorme trascendencia política del fallecimiento del príncipe, los sevillanos no escatimaron gastos a la hora de despedirse de él, ya que la inversión total que hizo el concejo de Sevilla, a juzgar por los datos que

120. Ladero Quesada, Miguel Ángel: «De Per Afán a Catalina de Ribera. Siglo y medio en la historia de un linaje sevillano (1371-1514)», En la España Medieval, 4 (1984), p. 461.

121. AMS, sección XV, Papeles del mayordomazgo, caja 83, rollo 695, fot. 77. 1497/12/01.

122. AMS, sección XV, Papeles del mayordomazgo, caja 83, rollo 695, fot. 77. 1497/12/o1.

123. Esta partida aparece recogida en un documento de la misma sección de Papeles del mayordomazgo que es prácticamente una repetición del documento citado en la nota anterior (AMS, sección XV, Papeles del mayordomazgo, caja 83, rollo 695, fot. 88. 1497/12/o1), aunque en él no se incluye esa partida (AMS, sección XV, Papeles del mayordomazgo, caja 83, rollo 695, fot. 77. 1497/12/01).

124. López Pérez, Miguel Ángel \& Redondo Jarillo, María Cristina: «Gastos de representación en Burgos: limosnas, regalos y honras fúnebres. Libros de actas municipales (1379-1476)», en GuerRERO NAVARRETE, Yolanda (coord.): Fiscalidad, sociedad y poder en las ciudades castellanas de la Baja Edad Media. Madrid, Ediciones de la Universidad Autónoma de Madrid, 2006, p. 172.

125. A modo de ejemplo, ver Idem, pp. 174-175. 
hemos podido extraer de los documentos conservados en la mencionada sección, ascendió a 221.490 maravedíes. Dentro de esa cantidad se incluyen, como es obvio, partidas de gastos de muy distinta naturaleza, que hemos agrupado en cuatro grandes bloques: construcción funeraria y elementos decorativos y de iluminación, desplazamientos, luto y, por último, misas. Todos esos bloques, con las diferentes partidas que se incluyen dentro de cada uno de ellos, se han registrado detalladamente en una tabla adjunta, a la que remitimos para un análisis pormenorizado de las cuantías.

Puede observarse que el volumen más elevado de gastos se corresponde con el primero de esos bloques, ya que la suma total de las distintas partidas asciende a 93.I65 maravedíes ${ }^{126}$. Sin duda, esa cifra tan alta responde al hecho de que en ella se incluyen los costes derivados de la realización del monumento funerario de la catedral -pieza clave de las honras fúnebres-y de todos los elementos decorativos y de iluminación que no podían faltar ni en el templo ni en la procesión previa a las exequias, dado que eran parte consustancial del ritual funerario regio. De hecho, en Écija, nos consta que se pagaron 77.I43 maravedíes a las personas que hicieron los túmulos y que se encargaron de adornar y de iluminar el templo en el que tuvieron lugar las exequias por el príncipe ${ }^{127}$. En el caso de Sevilla, dentro del bloque mencionado, resultan muy elevadas las partidas destinadas a carros de madera y a tablas, cuantificadas, respectivamente, en I9.486 y 7.975 maravedíes $^{128}$, lo que explica, a su vez, que se abonasen 22.658 maravedíes en jornales a los carpinteros «que fysieron e labraron en la yglesia mayor la madera de las honrras» ${ }^{129}$. Por otra parte, también es especialmente gravosa la partida destinada a

126. Las partidas destinadas a la cera y a las mazas de palo aparecen recogidas, respectivamente, en AMS, sección XV, Papeles del mayordomazgo, caja 83, rollo 695, fot. 106. 1497/11/20 y en AMS, sección XV, Papeles del mayordomazgo, caja 83, rollo 695, fot. 75. 1498/06/22. Sin embargo, todas las partidas restantes se pueden localizar en AMS, sección XV, Papeles del mayordomazgo, caja 83, rollo 695, fot. 77. 1497/12/o1 y en AMS, sección XV, Papeles del mayordomazgo, caja 83, rollo 695, fot. 80. 1497/11/30. Hemos podido comprobar que en la misma sección de Papeles del mayordomazgo aparece un documento sin fecha en el que se anotan gastos de materiales (AMS, sección XV, Papeles del mayordomazgo, caja 83, rollo 695, fot. 84). Sin embargo, sólo hemos contabilizado los 2.720 maravedíes de obras y materiales que aparecen en uno de los documentos citados con anterioridad (AMS, sección XV, Papeles del mayordomazgo, caja 83, rollo 695, fot. 77. 1497/12/01) porque imaginamos que los gastos de materiales que figuran en ese testimonio documental sin fecha se incluyen en este último documento. Por otra parte, en la suma de la partida correspondiente a los panes de oro y plata que aparece en este mismo documento hay un error porque el coste de los panes de oro fino, de los panes de plata y de los panes de oro bajo, que según consta en el documento ascendió a $2.147,5,187,5$ y 1.190 maravedíes respectivamente, suma 3.525 maravedíes y no 3.425 , que es la cantidad total que aparece anotada en el texto del documento y en el margen derecho del mismo (AMS, sección XV, Papeles del mayordomazgo, caja 83, rollo 695, fot. 77. 1497/12/o1). Por ello, en la tabla hemos registrado la cantidad de 3.525 maravedíes.

127. RUfo YSERN, Paulina: «El príncipe don Juan...», pp. 618-619.

128. AMS, sección XV, Papeles del mayordomazgo, caja 83, rollo 695, fot. 80. 1497/11/30. Sobre el gasto que se hizo en Daroca en madera y otros materiales, ver GARCíA MARCO, Luis Fernando \& GARCíA MARCO, Francisco Javier: «El impacto de la muerte del príncipe Juan en Daroca (1497-1498): poseía elegíaca y ritual urbano», Aragón en la Edad Media, X-XI (1993), pp. 329-330.

129. Como se puede comprobar en el documento correspondiente, la suma de todos los jornales es superior a la cantidad de 22.658 maravedíes que figura en el texto del documento y en el margen derecho del mismo (AMS, sección XV, Papeles del mayordomazgo, caja 83, rollo 695, fot. 80. 1497/11/30). Sin embargo, en otro documento que carece de fecha se puede observar que, en realidad, se pagaron 335 jornales de carpinteros a 60 maravedíes y 6 jornales a 50 maravedíes (AMS, sección XV, Papeles del mayordomazgo, caja 83, rollo 695, fot. 82). Por tanto, ello arroja un total de 
iluminación, ya que, como se puede comprobar analizando los datos de la tabla adjunta, la suma del gasto en cera y en antorcheras -este último recogido en tres asientos- ascendió a II.3Io maravedíes ${ }^{130}$. De igual modo, observando la tabla se constata que las cuatro partidas asignadas a la preparación de banderas y pendones supusieron un total de 8.380 maravedíes $^{131}$.

En el segundo de los bloques mencionados con anterioridad se incluyen los costes en concepto de desplazamientos, que suman un total de 67.290 maravedíes, según puede verse reflejado en la tabla ${ }^{132}$. Como es fácil suponer, detrás de semejante cantidad se encuentran las remuneraciones realizadas a todas aquellas personas que, tras conocerse en Sevilla la noticia de la muerte del príncipe, viajaron a la corte para dar el pésame a los reyes ${ }^{133} \mathrm{o}$ "para las cosas tocantes a las dichas honrras», así como también a algunos lugares del reino de Sevilla para invitar a las exequias a los miembros de la nobleza ${ }^{\mathrm{I} 34}$. El viaje a la corte para expresar las condolencias a los monarcas, que se inició hacia el I8 de octubre ${ }^{135}$, resultó especialmente caro. Sin embargo, hay que tener en cuenta que la distancia a recorrer fue larga, pues los reyes estuvieron en Salamanca y en algunas localidades cercanas desde el día 20 de octubre, llegando a Ávila el día 27, lugar en el que permanecieron hasta comienzos de noviembre ${ }^{136}$. Y a ello se añade que hubo que pagar el desplazamiento a cuatro personas: el alcalde mayor Martín Fernández Cerón, Gonzalo de Saavedra, mariscal y veinticuatro de Sevilla y los jurados Francisco Pinelo y Juan de la Fuente. Se entregaron diariamente 500 maravedíes a cada uno de los dos primeros y 250 a cada jurado para un viaje de 30 días, es decir, 45.000 maravedíes ${ }^{137}$. Pero ese viaje se alargó io y 9 días más respectivamente en el caso de Martín Fernández Cerón y Gonzalo de Saavedra y con la misma asignación

20.400 maravedíes. Si a esta cantidad se le añaden los 43 jornales de criados de carpinteros a 31 maravedíes y los 37 jornales de peones a 25 maravedíes que se anotan en el primero de los documentos citados (AMS, sección XV, Papeles del mayordomazgo, caja 83, rollo 695, fot. 80. 1497/11/30), que ascendieron a 1.333 y 925 maravedíes respectivamente, se obtiene un total de 22.658 maravedíes.

130. Sobre la cera, ver AMS, sección XV, Papeles del mayordomazgo, caja 83, rollo 695, fot. 106. 1497/11/20. Sobre las antorcheras, ver AMS, sección XV, Papeles del mayordomazgo, caja 83, rollo 695, fot. 77. 1497/12/o1. En relación a las hojas de hierro de las antorcheras, hemos anotado la cantidad de 1.680 maravedíes que figura en este último documento (AMS, sección XV, Papeles del mayordomazgo, caja 83, rollo 695, fot. 77. 1497/12/o1), ya que, aunque en un testimonio documental que carece de fecha esta partida aparece repetida y se le asigna una cantidad más alta (AMS, sección XV, Papeles del mayordomazgo, caja 83, rollo 695, fot. 82), nos ha parecido conveniente utilizar la cuantía que consta en el primero de esos documentos, que parece un documento más ordenado y seguramente más definitivo que este último.

131. AMS, sección XV, Papeles del mayordomazgo, caja 83, rollo 695, fot. 77. 1497/12/o1.

132. Los pagos a troteros y correos se insertan en AMS, sección XV, Papeles del mayordomazgo, caja 83, rollo 695, fot. 77. 1497/12/o1 y en AMS, sección XV, Papeles del mayordomazgo, caja 83, rollo 695, fot. 235. 1497/10/20. Por su parte, los pagos a los miembros del concejo que viajaron a la corte están recogidos en AMS, sección XV, Papeles del mayordomazgo, caja 83, rollo 695, fot. 104. 1497/10/18 y en AMS, sección XV, Papeles del mayordomazgo, caja 83, rollo 695, fot. 200. 1497/12/04.

133. AMS, sección XV, Papeles del mayordomazgo, caja 83, rollo 695, fot. 104. 1497/10/18; AMS, sección XV, Papeles del mayordomazgo, caja 83, rollo 695, fot. 200. 1497/12/04.

134. AMS, sección XV, Papeles del mayordomazgo, caja 83, rollo 695, fot. 77. 1497/12/o1.

135. De la lectura de un documento fechado ese día se deduce que la partida era inminente (AMS, sección XV, Papeles del mayordomazgo, caja 83, rollo 695, fot. 104. 1497/10/18).

136. Así consta en el itinerario elaborado por RUMEU DE ARMAS, Antonio: op. cit., p. 238.

137. AMS, sección XV, Papeles del mayordomazgo, caja 83, rollo 695, fot. 104. 1497/10/18. 
diaria, lo que supuso un coste de 9.500 maravedíes ${ }^{138}$, que, añadidos a la cantidad anteriormente mencionada, arroja un total de 54.500 maravedíes.

Pero, además de transmitir a los reyes el dolor por la muerte de su hijo, parece evidente que los miembros del concejo sevillano se preocuparon también de que ese sentimiento de tristeza fuera la nota dominante en la ciudad durante aquel otoño de I497. De hecho, aunque no poseemos noticias referidas a disposiciones de duelo, basta con analizar las abultadas partidas destinadas al luto para comprobar que el cabildo municipal no escatimó en la adquisición de tejidos de duelo, cuyo uso, como es sabido, era fundamental en la escenificación del dolor por la muerte regia o, en este caso, por el fallecimiento del malogrado príncipe. Como se puede observar en la tabla, la inversión en luto, que hemos incluido en el bloque tercero, fue de 43.035 maravedíes ${ }^{139}$, de los cuales, 38.235 costaron las 2.097 varas de jerga que se entregaron «a los caualleros e regidores e ofiçiales de esta çibdad e otras personas» ${ }^{140}$. Gracias a un documento que se inserta dentro de la sección mencionada, en el que aparece la nómina de caballeros a los que se proporcionó jerga, podemos constatar que, salvo algún caso excepcional, todos ellos recibieron I5 varas, aunque la lista no parece completa porque el monto total de varas de jerga es inferior ${ }^{141}$ a la cantidad a la que nos referimos con anterioridad ${ }^{142}$. En cualquier caso, es obvio que el coste total de la jerga que se entregó a los miembros del concejo sevillano supuso un desembolso importante para las arcas municipales. Por otra parte, el gasto de 2.800 maravedíes en varas de jerga para realizar las cubiertas de los caballos ${ }^{143}$ también resulta significativo, lo que prueba la importancia que tenía enjergar a esos animales de cara a la procesión fúnebre. De hecho, muchos años antes, con motivo de los funerales de Enrique II celebrados en Burgos, por las cubiertas de luto para los caballos se pagaron $\mathrm{I} .725$ maravedíes $^{144}$.

Por último, y como no podía ser de otro modo dado el protagonismo que tenían los oficios religiosos en el ritual funerario, hemos incluido un cuarto bloque en el que se anota el gasto en concepto de misas por el alma del príncipe, que ascendió a I8.00o maravedíes. En esa cantidad se incluyen los 3.000 maravedíes de limosna al monasterio de Santa María de las Cuevas «por el ányma» de este último ${ }^{145}$, de lo cual se deduce que en ese lugar se oficiaron misas por el príncipe, así como otros

138. AMS, sección XV, Papeles del mayordomazgo, caja 83, rollo 695, fot. 200. 1497/12/04.

139. Las partidas destinadas a varas de luto, por una parte, y a varas de jerga que se entregaron a personas particulares, por otra, se incluyen en AMS, sección XV, Papeles del mayordomazgo, caja 83, rollo 695, fot. 77. 1497/12/01. Por su parte, la partida correspondiente a jerga para los caballos aparece mencionada en AMS, sección XV, Papeles del mayordomazgo, caja 83, rollo 695, fot. 99. 1498/06/26.

140. AMS, sección XV, Papeles del mayordomazgo, caja 83, rollo 695, fot. 77. 1497/12/o1.

141. Se trata de un documento sin fecha (AMS, sección XV, Papeles del mayordomazgo, caja 83, rollo 695, fot. 86).

142. AMS, sección XV, Papeles del mayordomazgo, caja 83, rollo 695, fot. 77. 1497/12/01.

143. AMS, sección XV, Papeles del mayordomazgo, caja 83, rollo 695, fot. 99. 1498/06/26.

144. Archivo Municipal de Burgos, Libros de Actas capitulares, 1379, fols. 76v.-77r. 1379/07/09. Burgos. Documento citado por López Pérez, Miguel Ángel \& Redondo Jarillo, María Cristina: «Gastos de representación en Burgos: limosnas, regalos y honras fúnebres...», p. 179.

145. AMS, sección XV, Papeles del mayordomazgo, caja 83, rollo 695, fot. 102. 1497/10/30. 
I5.00o maravedíes «para pytanças de çiertas misas», aunque en este caso no se especifica el lugar de celebración de estas últimas ${ }^{\mathrm{I} 46}$. En Écija, las I.00o misas por su alma, por las que se entregaron I2.00o maravedíes en concepto de limosna, se repartieron por los monasterios e iglesias de esa localidad ${ }^{\mathrm{I} 47}$, por lo que es muy probable que en Sevilla sucediera lo mismo.

\section{CONCLUSIÓN}

En definitiva, como hemos intentado demostrar en el presente trabajo, a pesar de que el príncipe don Juan nunca había gozado de buena salud, una vez sorteados los peligros que acechaban durante la infancia, nada hacía presagiar su muerte en plena juventud y el mismo año en el que su enlace con Margarita de Austria parecía asegurar la sucesión dinástica. Por todo ello, el fallecimiento casi fulminante del único hijo varón de los Reyes Católicos a causa de una enfermedad cuya naturaleza no podemos precisar, provocó una tremenda conmoción, en medio de la cual lo que de verdad importaba era despedirlo como la ocasión merecía. Si como señaló J. D. González, con motivo de los funerales regios las ciudades se convertían en «un inmenso escenario urbano en el que representar la tragedia de la muerte» ${ }^{\mathrm{I} 48}$, resulta evidente que, a la luz de los numerosos datos inéditos aportados con anterioridad, tanto en Sevilla como en Córdoba se escenificó con especial magnitud el drama por el fallecimiento de don Juan, drama que, con diferentes actores, se representó de forma parecida en otros lugares de la Península, como tuvimos ocasión de comprobar. Como es obvio, para llevar a cabo esa representación, los concejos de ambas ciudades invirtieron elevadas sumas de dinero en imponentes decorados fúnebres y en luto, lo que, sin duda, tuvo que suponer un esfuerzo económico considerable, al que tuvieron que hacer frente también otros concejos peninsulares, según refleja la documentación conservada ${ }^{\mathrm{I} 4}$. Seguramente, durante aquel otoño de I497, poco importó desequilibrar las finanzas municipales porque lo verdaderamente importante fue llevar a escena esa manifestación del dolor colectivo por la muerte del joven príncipe.

146. AMS, sección XV, Papeles del mayordomazgo, caja 83, rollo 695, fot. 103. 1497/10/30.

147. Archivo Municipal de Écija, Actas capitulares, leg. 1, fols. 421v.-425v. 1497/10/16. Écija. Documento citado por Rufo YSERn, Paulina: «El príncipe don Juan...», p. 624 y p. 626.

148. GonzÁlez ARCE, José Damián: Apariencia y poder. La legislación suntuaria castellana en los siglos XIII y XV. Jaén, Universidad de Jaén, 1998, p. 226.

149. Ver, en ese sentido, la interesante documentación referida a los gastos derivados de las exequias del príncipe que aparece recogida en Pérez Bustamante, Rogelio \& Calderón ORTEGA, José Manuel: op. cit., pp. 314-375. 
GASTOS DE LAS EXEQUIAS DEL PRÍNCIPE DON JUAN EN SEVILLA

\begin{tabular}{|c|c|c|c|}
\hline & & Partidas & Gasto \\
\hline \multirow{28}{*}{$\begin{array}{l}\text { 1. Monumento } \\
\text { funerario y elementos } \\
\text { decorativos y de } \\
\text { iluminación }\end{array}$} & \multirow{13}{*}{$\begin{array}{l}\text { 1.1. Monumento } \\
\text { funerario }\end{array}$} & Obras y materiales & $2.720 \mathrm{mrs}$. \\
\hline & & Carretadas de madera & $672 \mathrm{mrs}$ \\
\hline & & Madera de álamo & $1.319 \mathrm{mrs}$. \\
\hline & & Tablas & $7.975 \mathrm{mrs}$. \\
\hline & & Carros de madera & $19.486 \mathrm{mrs}$ \\
\hline & & Montaje clavos & $3.160 \mathrm{mrs}$ \\
\hline & & Panes de oro y plata & $3.525 \mathrm{mrs}$ \\
\hline & & Pintura & $1.000 \mathrm{mrs}$. \\
\hline & & $\begin{array}{l}\text { Construcción cama, estrados y } \\
\text { asientos }\end{array}$ & $4.000 \mathrm{mrs}$. \\
\hline & & Cabezas de yeso para la cama & $620 \mathrm{mrs}$. \\
\hline & & Jornales de los carpinteros & $22.658 \mathrm{mrs}$ \\
\hline & & Desmontar la construcción & $1.375 \mathrm{mrs}$ \\
\hline & & Totales parciales & $68.510 \mathrm{mrs}$ \\
\hline & \multirow{15}{*}{$\begin{array}{l}\text { 1.2. Elementos } \\
\text { decorativos y de } \\
\text { iluminación }\end{array}$} & Dorar escudo & $600 \mathrm{mrs}$. \\
\hline & & Pintar y teñir algunos elementos & $3.500 \mathrm{mrs}$ \\
\hline & & Lienzo de las banderas & $7.350 \mathrm{mrs}$ \\
\hline & & Teñido del lienzo de las banderas & $630 \mathrm{mrs}$ \\
\hline & & Confección de las banderas & $200 \mathrm{mrs}$. \\
\hline & & $\begin{array}{l}\text { Realización de flocaduras de las } \\
\text { banderas, cordones y botones de los } \\
\text { pendones }\end{array}$ & $200 \mathrm{mrs}$. \\
\hline & & Fabricación y arreglo de antorcheras & $200 \mathrm{mrs}$ \\
\hline & & Hojas de hierro de las antorcheras & $1.680 \mathrm{mrs}$. \\
\hline & & Tachuelas de las antorcheras & $160 \mathrm{mrs}$ \\
\hline & & Cera & $9.270 \mathrm{mrs}$. \\
\hline & & Tijeras para despavesar las velas & $200 \mathrm{mrs}$ \\
\hline & & Cabezas de palo & $40 \mathrm{mrs}$. \\
\hline & & Mazas de palo & $265 \mathrm{mrs}$. \\
\hline & & Otros gastos & $360 \mathrm{mrs}$. \\
\hline & & Totales parciales & $24.655 \mathrm{mrs}$ \\
\hline \multicolumn{3}{|c|}{$\begin{array}{l}\text { Total gastos en el monumento funerario y en los } \\
\text { elementos decorativos y de iluminación }\end{array}$} & $93.165 \mathrm{mrs}$ \\
\hline \multirow{3}{*}{\multicolumn{2}{|c|}{ 2. Desplazamientos }} & Troteros y correos & $12.790 \mathrm{mrs}$. \\
\hline & & $\begin{array}{l}\text { Viaje a la corte de varios miembros } \\
\text { del concejo }\end{array}$ & $54.500 \mathrm{mrs}$ \\
\hline & & Totales parciales & $67.290 \mathrm{mrs}$ \\
\hline \multirow{4}{*}{ 3. Luto } & & Varas de luto & $2.000 \mathrm{mrs}$. \\
\hline & & Jerga de personas particulares & $38.235 \mathrm{mrs}$ \\
\hline & & Jerga de caballos & $2.800 \mathrm{mrs}$ \\
\hline & & Totales parciales & $43.035 \mathrm{mrs}$ \\
\hline \multicolumn{3}{|l|}{ 4. Misas } & $18.000 \mathrm{mrs}$. \\
\hline \multicolumn{3}{|l|}{ Total gastos exequias } & $221.490 \mathrm{mrs}$. \\
\hline
\end{tabular}




\section{BIBLIOGRAFÍA}

AlcAlÁ Galve, Ángel \& SANz Hermida, Jacobo: Vida y muerte del príncipe don Juan. Historia y literatura. Valladolid, Junta de Castilla y León, I999.

Bernis Madrazo, Carmen: Trajes y modas en la España de los Reyes Católicos, vol. II. Los hombres. Madrid, Instituto Diego Velázquez del Consejo superior de investigaciones científicas, I979.

CABrera SÁnchez, Margarita: Nobleza, oligarquía y poder en Córdoba al final de la Edad Media. Córdoba, Servicio de Publicaciones de la Universidad de Córdoba y Obra Social y Cultural de Cajasur, 1998.

CABRERA SÁnchez, Margarita: «Funerales regios en la Castilla bajomedieval», Acta historica et archaeologica mediaevalia, 22/2 (2001), pp. 537-564.

CABrera Sánchez, Margarita: «La muerte de los niños de sangre real durante el Medievo. Aproximación al tema a través de las crónicas», En la España Medieval, 3I (2008), pp. 217-248.

CABrera SÁnchez, Margarita: «La muerte de los miembros de la realeza hispánica medieval a través de los testimonios historiográficos», En la España Medieval, 34 (2011), pp. 97-I32.

CABRERA SÁNCHEz, Margarita: «El rey ha muerto: ritos, funerales y entierro de la realeza hispánica medieval», en López OJEDA, Esther (coord.): De la tierra al cielo. Ubi sunt qui ante nos in hoc mundo fuere?, XXIV Semana de Estudios Medievales. Logroño, Instituto de Estudios Riojanos, 20I4, pp. 239-26o.

CABrera SÁnchez, Margarita: «Técnicas de conservación post mortem aplicadas a los miembros de la realeza hispánica medieval», Edad Media. Revista de Historia, i6 (2015), pp. I75-I98.

CAmón Aznar, José: Sobre la muerte del príncipe don Juan. Madrid, Real Academia de la Historia, I963.

CARDAILlaC, Louis: L'Espagne des Rois Catholiques. Le prince don Juan, symbole de l'apogée d'un règne, I474-I497. Paris, Éditions Autrement, 2000.

Castro Quesada, Américo: Teresa la Santa, Gracián y los separatismos con otros ensayos. Madrid, Alfaguara, 1972.

Córdoba de la Llave, Ricardo: La industria medieval de Córdoba. Córdoba, Obra Cultural de la Caja Provincial de Ahorros de Córdoba, I990.

Fraser, Antonia: Las seis esposas de Enrique VIII. Barcelona, Vergara, 2005.

García Marco, Luis Fernando \& García Marco, Francisco Javier: «El impacto de la muerte del príncipe Juan en Daroca (I497-I498): poseía elegíaca y ritual urbano», Aragón en la Edad Media, X-XI (I993), pp. 307-337.

García Pérez, Francisco José \& GonZÁlez Arce, José Damián: «Ritual, jerarquías y símbolos en las exequias reales de Murcia (siglo XV)», Miscelánea Medieval Murciana, XIX-XX (I995-I996), pp. I29-I38.

Gaude-Ferragu, Murielle: «L'honneur de la reine: la mort et les funérailles de Charlotte de Savoie (I ${ }^{\mathrm{er}}$-I4 décembre I483)», Revue historique, 652 (octubre de 2009), pp. 779-804.

GONZÁlEZ ARCE, José Damián: Apariencia y poder. La legislación suntuaria castellana en los siglos XIII y XV. Jaén, Universidad de Jaén, I998.

GoNZÁlEZ ARCE, José Damián: La casa y corte del príncipe don Juan (I478-I497). Economía y etiqueta en el palacio del hijo de los Reyes Católicos. Sevilla, Sociedad Española de Estudios Medievales, 2016. 
GonZalo SÁNCHEZ-Molero, José Luis: «El príncipe Juan de Tastámara, un exemplum vitae para Felipe II en su infancia y juventud», Hispania, LIX/3, 203 (septiembre-diciembre de i999), pp. 87I-896.

JORDAN, Wilbur Kitchener: Edward VI: the young king. The protectorship of the duke of Somerset. Cambridge/Massachusetts, The Belknap Press of Harvard University Press, 1968.

Ladero Quesada, Miguel Ángel: «De Per Afán a Catalina de Ribera. Siglo y medio en la historia de un linaje sevillano (I37I-I5I4)», En la España Medieval, 4 (I984), pp. 447-497.

Laguna Paúl, Teresa: «Devociones reales e imagen pública en Sevilla», Anales de Historia del Arte, 23/II (2013), pp. I27-I57.

López PÉREZ, Miguel Ángel \& REDONDO JARILlo, María Cristina: «Gastos de representación en Burgos: limosnas, regalos y honras fúnebres. Libros de actas municipales (I379-I476)», en Guerrero Navarrete, Yolanda (coord.): Fiscalidad, sociedad y poder en las ciudades castellanas de la Baja Edad Media. Madrid, Ediciones de la Universidad Autónoma de Madrid, 2006, pp. 15I-202.

Maura, Duque de: El príncipe que murió de amor. Don Juan, primogénito de los Reyes Católicos. Madrid, Aldebarán Ediciones, 2000.

Nieto Soria, José Manuel: Ceremonias de la realeza. Propaganda y legitimación en la Castilla Trastámara. Madrid, Nerea, I993.

Pereda Espeso, Felipe: Las imágenes de la discordia. Política y poética de la imagen sagrada en la España del Cuatrocientos. Madrid, Marcial Pons, 2007.

Pérez Bustamante, Rogelio \& Calderón Ortega, José Manuel: Don Juan príncipe de las Españas (I478-I479). Colección diplomática. Madrid, Dykinson, I999.

Pino García, José Luis del: «El concejo de Córdoba a fines de la Edad Media: estructura interna y política municipal», Historia. Instituciones. Documentos, 20 (I993), pp. 355-40I.

Romero ABAD, Antonio del Rocío: «Fiestas de la vida y de la muerte en la Sevilla del siglo $\mathrm{XV} »$, Las ciudades andaluzas (siglos XIII-XVI), Actas del VI Coloquio Internacional de Historia Medieval de Andalucía, Estepona, I99o, López DE Coca CASTAÑER, José Enrique \& GalÁN SÁNCHEz, Ángel (coords.), Málaga, Universidad de Málaga, I99I, pp. 289 -297.

Romero CABEllo, Raúl: Microbiología y parasitología humana. Bases etiológicas de las enfermedades infecciosas y parasitarias. México, Editorial Médica Panamericana, 2007.

Rufo Ysern, Paulina: «El príncipe don Juan de Trastámara, señor de Écija», Historia. Instituciones. Documentos, 3I (2004), pp. 605-629.

Rumeu de Armas, Antonio: Itinerario de los Reyes Católicos I474-I5I6. Madrid, Consejo superior de investigaciones científicas, I974. 

Calidad de Revistas

científicas Españolas

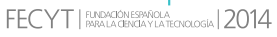

SERIE III HISTORIA MEDIEVAL

REVISTA DE LA FACULTAD DE GEOGRAFÍA E HISTORIA
AÑO 2018

ISSN: 0214-9745

E-ISSN 2340-1362

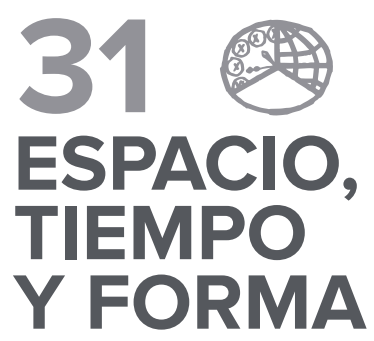

GREGoRIO DEL SER QUIJANO

Carmelo Luis López, In Memoriam

\section{Artículos · Articles}

29 Soha ABBoud Haggar

Un resumen del tratado jurídico de Al-Tafrí: el Manuscrito Árabe 1233 del Monasterio de El Escorial y su supuesta relación con Leyes de Moros

EDUARDo Aznar VALLejo

Norma y conflicto en la navegación castellana bajomedieval

69 Carlos Barquero Goñ

Transferencias de recursos de la Orden de San Juan desde España hasta el Mediterráneo Oriental durante la Edad Media

\section{Margarita Cabrera Sánchez}

La muerte del príncipe Don Juan. Exequias y duelo en Córdoba y Sevilla durante el otoño de 1497

\section{Francisco de Paula Cañas Gálvez}

Primogenitura, continuidad dinástica y legitimitad instituciona en Castilla a principios del siglo XV: Catalina de Trastámara, Princesa de Asturias (1422-†1424)

\section{Paloma Cuenca Muñoz}

El códice visigótico de los Moralia in lob, ms. lat. 83 de la John Rylands Library de Manchester

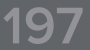

\section{JOSÉ MARÍA DIAGO JIMÉNEZ}

Las instituciones educativas de carácter religioso en el reino hispanovisigodo de los siglos VI y VII a través de los cánones conciliares y las reglas monásticas

MARÍA Díez Yáñez

La Ética aristotélica en Castilla: las bibliotecas universitarias medievales y prerrenacentistas

\section{Estefanía Ferrer del Río}

Rodrigo de Mendoza, I Marqués del Cenete y I Conde del Cid: paralelismos entre su biografía y su pretendida genealogía

\section{ALEJANDRo García Morilla \\ Escritura publicitaria de transición: entre la visigótica y la carolina.} El paradigma burgalés

María Dolores García Oliva

Señores contra campesinos: un conflicto por la tierra en Mirabel a finales de la Edad Media y principios de los Tiempos Modernos (1488-c. 1520)
34.3 jaime García Carpintero lópez de Mota

La hospitalidad santiaguista a finales de la Edad Media: el proyecto de reconstrucción del hospital de Alarcón

377 LAURA DA GRACIA

La posesión agraria individual en los registros notariales de Fuente el Sol (1481-1482

4.03 Mauricio Herrero Jiménez

El valor de los documentos reales en los procesos de la Real Chancillería de Valladolid

431 Miguel José López-Guadalupe Pallarés

Procesos de señorialización en los concejos de la Extremadura castellano-leonesa. Un estado de la cuestión

455 Ángel Martínez Catalán

Las rentas decimales del cabildo catedralicio de Cuenca a inicios del siglo XV (1400-1432)

4.83 Gonzalo Oliva Manso

Cien años de moneda en Castilla (1172-1268). El siglo del maravedí de oro

521 jesús Olivet García-Dorado

El cabildo de curas y beneficiados de Toledo en la segunda mitad del siglo XV. Composición y aspectos institucionales (1455-1488)

547 Mariel PÉrez

Clérigos rurales, comunidades y formación de las estructuras parroquiales en la diócesis de León (siglos XI-XIII)

575 Milagros Plaza Pedroche

La Orden de Calatrava en la Baja Edad Media (1350-1500): repaso historiográfico

597 Pedro Andrés Porras Arboledas

La pervivencia del Fuero de Cuenca en los inicios de la Modernidad: el testimonio de los fueros de Consuegra y Requena

619 Juan Pablo Rubio Sadia

Los mozárabes frente al rito romano: balance historiográfico de una relación polémica

SANDRA SUÁREZ GARCíA

Los habices de la Vega de Granada como forma de conocimiento del reino nazarí y su transformación tras la conquista: la alquería de La Zubia 


\section{1}

\section{ESPACIO,}

\section{TIEMPO}

\section{Y FORMA}

SERIE III HISTORIA MEDIEVAL

REVISTA DE LA FACULTAD DE GEOGRAFÍA E HISTORIA

\section{De medievalistas ilustres · On Renowned Medievalists}

671 Francisco Abad Nebot

Entradas para un Diccionario

\section{Libros $\cdot$ Books}

679 Almagro Vidal, Clara, Paisajes medievales en el Campo de Calatrava (CARLos BARQUero GoÑI)

681 Carvajal Castro, Álvaro, Bajo la máscara del Regnum. La monarquía asturleonesa en León (854-1037) (JOSÉ MANUEL RODRÍGUEZ GARCíA)

683 Fuente Pérez, María Jesús, Violante de Aragón, reina de Castilla (ANA ECHEVARRía ARsuaga)

687 Martín Prieto, Pablo, Historia del pensamiento medieval: filosofia y teología (FRANCISCO LEÓN FLORIDO)

689 Pardo de Guevara y Valdés, Eduardo (ed.), Mujeres con poder en la Galiciamedieval (siglos XIII-XV). Estudios, biografías y documentos (ENRIQUe CANTERA MONTENEGRO)

693 Ríos Saloma, Martín (ed.), El mundo de los conquistadores (Jessica Ramírez MéndeZ)

690 Solórzano Telechea, Jesús, Arízaga Bolumburu, Beatriz y BOCHACA, Michel (eds.), Las sociedades portuarias de la Europa atlántica en la Edad Media (ANTONIO ORTEGA VILLOSLADA)

703 VAL VALDIVIEso, María Isabel del (coord.), El agua en el
imaginario medieval. Los reinos ibéricos en la Baja Edad Media (MARÍA Jesús Fuente)

707 Villar García, Luis Miguel, Archivo Municipal de Segovia. Documentación medieval, 1166-1474 (ENRIQUE CANTERA MONTENEGRO) 